\title{
PthAW1, a Transcription Activator-Like Effector of Xanthomonas citri subsp. citri, Promotes Host-Specific Immune Responses
}

\author{
Doron Teper, Jin Xu, Sheo Shankar Pandey, and Nian Wang ${ }^{\dagger}$ \\ Citrus Research and Education Center, Department of Microbiology and Cell Science, Institute of Food and Agricultural \\ Sciences, University of Florida, 700 Experiment Station Road, Lake Alfred, FL 33850, U.S.A.
}

Accepted 8 May 2021.

\begin{abstract}
Citrus canker disease caused by Xanthomonas citri subsp. citri is one of the most destructive diseases in citrus. $X$. citri subsp. citri pathotypes display different host ranges. $X$. citri subsp. citri strain $\mathbf{A}\left(X c c^{\mathbf{A}}\right)$ causes canker disease in most commercial citrus varieties, whereas strain $\mathrm{AW}\left(X c c^{\mathrm{AW}}\right)$, which is genetically similar to $X c c^{\mathbf{A}}$, infects only lime and alemow. Understanding the mechanism that determines the host range of pathogens is critical to investigating and utilizing host resistance. We hypothesized that $X c c^{\mathrm{AW}}$ would undergo mutations in genes that restrict its host range when artificially inoculated into incompatible citrus varieties. To test this hypothesis, we used an experimental evolution approach to identify phenotypic traits and genetic loci associated with the adaptation of $X c c^{\mathrm{AW}}$ to incompatible sweet orange. Repeated inoculation and reisolation cycles improved the ability of three independent $X c c^{\mathrm{AW}}$ strains to colonize sweet orange. Adapted $X c c^{\mathrm{AW}}$ strains displayed increased expression of type III secretion system and effector genes. Genome sequencing analysis indicated that two of the adapted strains harbored mutations in pthAW1, a transcription activator-like effector (TALE) gene, that corresponded to the removal of one or two repeats from the central DNA-binding repeat region. Introduction of the original but not the adapted $p t h A W 1$ variants into $X c c^{\mathrm{A}}$ abolished its ability to cause canker symptoms in sweet orange, Meyer lemon, and clementine but not in other $X c c^{\mathrm{AW}}$-resistant citrus varieties. The original $p t h A W 1$, when expressed in $X c c^{\mathrm{A}}$, induced ion leakage and the expression of pathogenesis-related genes but had no effect on $C S L O B 1$ expression in sweet orange. Our study has identified a novel host-specific avirulence TALE and demonstrated active adaptive rearrangements of the TALE repeat array during host adaptation.
\end{abstract}

${ }^{\dagger}$ Corresponding author: N. Wang; nianwang@ufl.edu

Funding: This project was supported by the United States Department of Agriculture-National Institute of Food and Agriculture Plant Biotic Interactions Program 2017-67013-26527, Florida Citrus Initiative Program, and Citrus Research and Development Foundation.

*The $e$-Xtra logo stands for "electronic extra" and indicates that supplementary materials are published online.

The author(s) declare no conflict of interest.

(c) (1) () $\odot$ Copyright $(\odot 2021$ The Author(s). This is an open access article distributed under the CC BY-NC-ND 4.0 International license.
Keywords: citrus, experimental evolution, hypersensitive response, host specificity, PthA, PthAW1, PthAW2, transcription activatorlike effector, Xanthomonas citri

Bacterial pathogens use diverse strategies to adapt to their hosts. Pathogenic bacteria can be roughly divided into specialists, which harbor a narrow host range, and generalists, which have a broad host range. It has been suggested that adaptation to specific hosts is accompanied by a tradeoff of multiple traits that improve longterm colonization of a specific host at the expense of traits that are required for the infection and colonization of other hosts (Woolhouse et al. 2001). Factors such as transmission, attachment, nutrient acquisition, suppression of host immune responses, effectors, and toxins are significant in dictating the host range of pathogens of plants and animals (Bäumler and Fang 2013).

Most studies on the host specificity of plant-pathogenic bacteria have focused on the genetic resistance of plant species or varieties of specific crops to pathogen elicitors (Gill et al. 2015; Zhang et al. 2013). The gene-for-gene model developed by Flor in the mid20th century states that host restriction of specific pathogens is based on recognition of a specific pathogen avirulence (avr) elicitor by a resistance $(R)$ gene product of a resistant crop (Flor 1971; Gassmann and Bhattacharjee 2012).

Plant $R$ genes usually encode either transmembrane receptor-like kinases or intracellular nucleotide-binding site leucine-rich repeat (NBS-LRR) proteins that initiate host immune responses upon direct or indirect recognition of a specific avr elicitor (Cesari 2018). The immune responses triggered upon recognition of an Avr protein by a known $\mathrm{R}$ receptor can be accompanied by hypersensitive response (HR) and rapid localized cell death in the infected areas, which is hypothesized to restrict further pathogen spread (Balint-Kurti 2019). Many avr genes and specific $R-a v r$ gene interactions have been identified. The most established bacterial Avr proteins are effectors translocated through the type 3 secretion system (T3SS) (Alfano and Collmer 2004). Avr effectors determine pathogen specificity to plant varieties within the same crop species and, in a few cases, between plant species. For example, the HopQ/ XopQ effectors of Pseudomonas syringae pv. tomato and Xanthomonas euvesicatoria restrict these pathogens from infecting Nicotiana benthamiana (Schwartz et al. 2015; Wei et al. 2007), and the AvrBsT effector of $X$. perforans restricts pathogens from infecting pepper (Kim et al. 2010). However, the determinants of the host specificity of many bacterial pathogens remain unknown.

Xanthomonas is a large genus of plant-pathogenic bacteria that cause diseases in hundreds of crops (An et al. 2020). Xanthomonas spp. are usually specialized, in that they infect a narrow range of hosts, and the determinants of their host specificity are poorly 
understood (An et al. 2020). Nonetheless, type III effectors, microbe-associated molecular patterns, lipopolysaccharides (LPS), transcriptional regulators, and chemotactic sensors are suggested as key determinants of host specificity (Jacques et al. 2016).

Citrus canker is caused by $X$. citri subsp. citri and $X$. citri subsp. aurantifolia (Ference et al. 2018). It was considered to be the most economically important citrus disease before the arrival of the notorious citrus huanglongbing in countries of North and South America (Ference et al. 2018; Wang 2019; Wang et al. 2017; Yuan et al. in press). Most commercial citrus varieties are susceptible to citrus canker (Favaro et al. 2020; Ference et al. 2020). Currently, citrus canker management is mainly based on copper-based bactericides ( $\mathrm{Li}$ and Wang 2014; Gochez et al. 2018). In addition, antimicrobials such as streptomycin and oxytetracycline were approved to be used to treat citrus canker in some citrusproducing regions (e.g., Florida) (Hu and Wang 2016; J. Li et al. 2019). It is characterized by elevated pustules on the aerial surface of citrus plants (Ference et al. 2018). These symptoms are caused by transcriptional induction of the plant CsLOBI gene, the canker susceptibility gene, by bacterial transcription activator-like effectors (TALEs) such as PthA4 or PthAW2 (Abe and Benedetti 2016; Duan et al. 2018; Hu et al. 2014; Yan and Wang 2012; Zhang et al. 2017). Of note, this critical feature has been utilized to control canker by modifying the TALEbinding element or coding region of $C S L O B 1$ using CRISPR technology (Jia and Wang 2014, 2020; Jia et al. 2017a, b, 2019; Peng et al. 2017; Wheatley and Yang in press). Moreover, pthA4 and other T3SS effectors and many important virulence traits such as LPS (Li and Wang 2012; Yan et al. 2012), extracellular polysaccharide (Rigano et al. 2007), biofilm (Li and Wang 2011, 2014), quorum sensing (L. Li et al. 2019), and periplasmic proteins (Zhou et al. 2015) also contribute to X. citri subsp. citri infection and colonization as well as the development of canker symptoms. These virulence traits are delicately regulated in response to cues from the host and environment (Andrade et al. 2014; Guo et al. 2011; Teper et al. 2019; Zhang et al. 2019; Zhou et al. 2017, 2018). X. citri subsp. citri is divided into several pathotypes according to host range and ability to elicit HR in different citrus varieties. $X$. citri subsp. citri strain A $\left(X c c^{\mathrm{A}}\right)$ is the most prevalent canker pathogen worldwide. Two groups of $X$. citri subsp. citri strains that are genetically similar to $X c c^{\mathrm{A}}$ strains but have restricted host ranges are strain $\mathrm{AW}\left(X c c^{\mathrm{AW}}\right)$ and strain $\mathrm{A}^{*}$ $\left(X c c^{\mathrm{A}^{*}}\right.$ ) (Sun et al. 2004; Vernière et al. 1998). $X c c^{\mathrm{AW}}$ and $X c c^{\mathrm{A}^{*}}$ only infect lime and alemow plants (Brunings and Gabriel 2003; Sun et al. 2004). $X c c^{\mathrm{AW}}$ elicits HR in grapefruit, whereas $X c c^{\mathrm{A}^{3}}$ does not cause any symptoms (Brunings and Gabriel 2003).

Genomic studies have demonstrated that $X c c^{\mathrm{A}}, X c c^{\mathrm{AW}}$, and $X c c^{\mathrm{A}^{*}}$ are distinct from one another in spite of their similarity (Patané et al. 2019; Y. Zhang et al. 2015). A comparative genome analysis of $X c c^{\mathrm{AW}}$ strain Aw12879 and $X c c^{\mathrm{A}}$ strain 306 identified genome rearrangements, the loss and gain of multiple large genomic islands, alteration of the LPS-coding gene cluster, and an altered T3SS effector arsenal (Jalan et al. 2013a). The T3SS effector XopAG (referred to as AvGf1 in X. citri subsp. citri or AvrGf2 in $X$. citri subsp. aurantifolia) only occurs in lime-restricted strains of $X$. citri subsp. citri and $X$. citri subsp. aurantifolia (Gochez et al. 2015; Rybak et al. 2009). XopAG elicits HR in both grapefruit and sweet orange, and disruption of the effector improves the ability of host-restricted $X$. citri subsp. citri and $X$. citri subsp. aurantifolia strains to colonize grapefruit; therefore, XopAG is classified as an Avr effector (Jalan et al. 2013a; Rybak et al. 2009). However, disruption of the XopAG effector does not expand the host range of $X c c^{\mathrm{AW}}$ to sweet orange, and the effector is absent in $X c c^{\mathrm{A}^{*}}$ strains with host specificity similar to that of $X c c^{\mathrm{AW}}$ (Jalan et al. 2013a; Patané et al. 2019), which suggests that other determinants of the host specificity of $X c c^{\mathrm{AW}}$ have yet to be identified.
We hypothesized that $X c c^{\mathrm{AW}}$ would undergo mutations in genes that restrict its host range when artificially inoculated into incompatible citrus varieties. To test this hypothesis, we used an experimental evolution approach (Remigi et al. 2019; Trivedi and Wang 2014) to perform repeated inoculation of resistant sweet orange to identify traits and genomic elements associated with the host specificity of $X c c^{\mathrm{AW}}$.

\section{RESULTS}

AvrGf1 is not the sole determinant of the host specificity of $X c c^{\mathrm{AW}}$.

A previous study demonstrated that disrupting the avrGfl effector in the $X c c^{\mathrm{AW}}$ strain enables bacteria to infect grapefruit but not sweet orange (Jalan et al. 2013a). We examined whether AvrGf1 is involved in the immunity of sweet orange to $X c c^{\mathrm{AW}}$. Sweet orange and key lime plants were inoculated with wild-type $X c c^{\mathrm{AW}}$ strain Xcaw12879 (hereafter $X c c^{\mathrm{AW}}$ ), wild-type $X c c^{\mathrm{A}}$ strain 306 (hereafter $X c c^{\mathrm{A}}$ ), $X c c^{\mathrm{AW}} \Delta a v r G f 1$, and $X c c^{\mathrm{A}}$ carrying a plasmid harboring avrGfl from $X c c^{\mathrm{AW}}$. Although all strains were able to

A

A Sweet orange Key lime

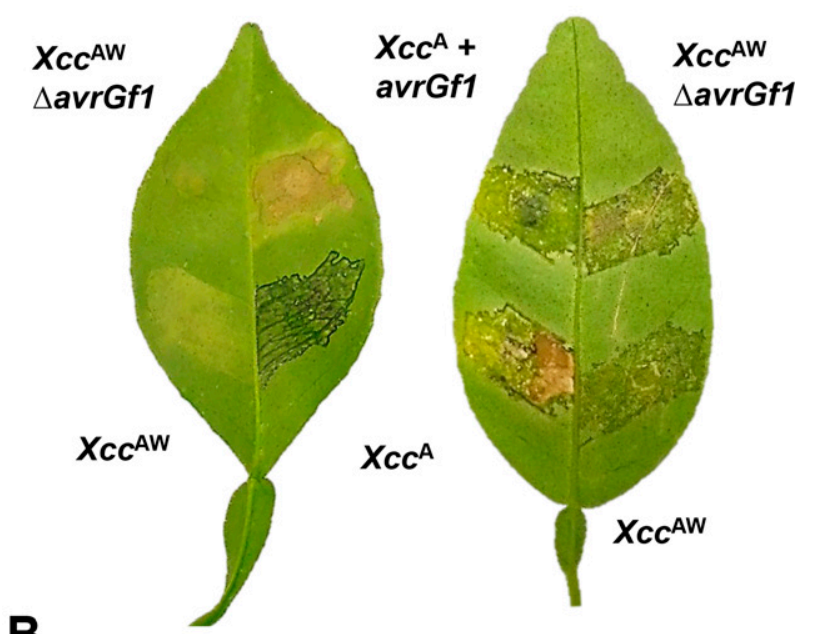

B
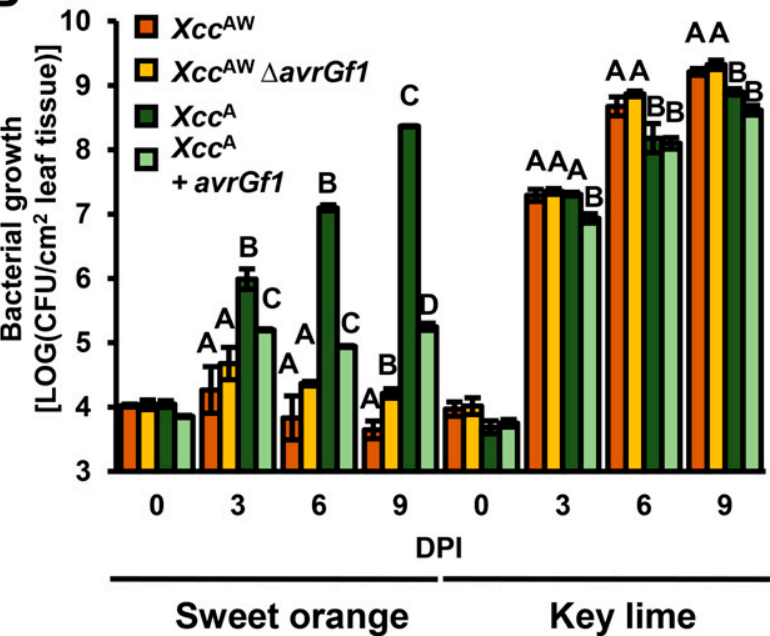

Key lime

Fig. 1. AvrGf1 induces hypersensitive response in sweet orange. Indicated bacterial cultures were syringe inoculated $\left(10^{8} \mathrm{CFU} / \mathrm{ml}\right.$ for $\mathrm{A}$ and $10^{6}$ $\mathrm{CFU} / \mathrm{ml}$ for B) into sweet orange or key lime leaves. A, Pictures were taken 7 days postinoculation (DPI). B, In planta bacterial populations were monitored on the indicated days postinoculation. Data are means \pm standard error of three biological replicates. Letters denote significant differences based on analysis of variance and comparisons of all pairs using Student's $t$ test $(P<0.05)$. Experiments were repeated twice (for key lime) or four times (for sweet orange), with similar results. 
cause canker symptoms in key lime (Fig. 1A), we only observed canker symptoms in sweet orange inoculated with the wild-type $X c c^{\mathrm{A}}$ strain (Fig. 1A). Sweet orange leaves inoculated with $X c c^{\mathrm{AW}}$ exhibited chlorotic symptoms and occasional cell death 4 to 7 days postinoculation (DPI), whereas $X c c^{\mathrm{AW}} \Delta a v r G f 1$ did not display any apparent symptoms at these time points (Fig. 1A). In addition, $X c c^{\mathrm{AW}}$ and $X c c^{\mathrm{AW}} \Delta a v r G f 1$ were not able to efficiently colonize sweet orange, and bacterial populations only reached $10^{4}$ to $5 \times$ $10^{4} \mathrm{CFU} / \mathrm{cm}^{2}$ (Fig. 1B). The introduction of $a v r G f 1$ into $X c c^{\mathrm{A}}$ significantly decreased its colonization of sweet orange, and bacterial titers were reduced by approximately 1,000-fold compared with the wild-type $X c c^{\mathrm{A}}$ strain (Fig. 1B). In addition, $X c c^{\mathrm{A}}$ containing avrGfl elicited HR at 3 to 7 DPI (Fig. 1A).

Our data suggest that AvrGf1 is recognized in sweet orange as an avr factor. However, it appears that the immunity of sweet orange to $X c c^{\mathrm{AW}}$ relies on other determinants in addition to AvrGf1.

\section{Experimentally adapted $X c c^{\mathrm{AW}}$ strains display} improved colonization of sweet orange.

Next, we used an experimental evolution approach to identify genes that determine the host specificity of $X c c^{\mathrm{AW}}$. Three strains of $X c c^{\mathrm{AW}}$ were inoculated and reisolated from sweet orange leaves for 30 to 45 passages (Fig. 2A). Symptoms and bacterial populations were determined for each passage (Fig. 2B). Colonization of sweet orange improved significantly for all three strains and adapted $X c c^{\mathrm{AW}}$ bacteria were able to colonize in sweet orange to approximately $10^{6}$ to $10^{7} \mathrm{CFU} / \mathrm{cm}^{2}$ after 5 to 15 passages (Fig. 2B). Although all adapted strains (named $X c c^{\text {AWAdA }}, X c c^{\text {AWAdB }}$, and $X c c^{\text {AWAdC }}$ ) showed improved colonization, none of them were able to promote canker symptoms in sweet orange. Instead, the three adapted strains induced significantly stronger HR in sweet orange than wildtype $X c c^{\mathrm{AW}}$ (Fig. 3A and B).

When inoculated into key lime, the three adapted strains colonized the plant significantly faster than the wild type at the early stage. However, all three strains reached similar titers as the wild type between 6 and 9 DPI. In addition, the three strains caused stronger and earlier canker symptoms in key lime (Fig. $3 \mathrm{~A}$ and $\mathrm{C}$ ). The three strains also showed enhanced growth in sweet orange, reached maximal bacterial titers at 3 DPI, and maintained the population until 9 DPI (Fig. 3C). In addition, bacterial growth was monitored in vitro in nutrient broth $(\mathrm{NB})$ and the plant-mimicking medium XVM2. All adapted strains exhibited growth kinetics similar to the wild-type strain in both media, except at the late stage in NB (Supplementary Fig. S1A and B).

To identify factors that were selected during adaptation, we monitored the three adapted $X c c^{\mathrm{AW}}$ strains for various virulence traits. We did not observe significant differences in hydrolase activity, exopolysaccharide (EPS) production, LPS profile, or biofilm formation compared with the wild-type strain (Supplementary Fig. S2). One of the adapted strains, $X c c^{\text {AWAdC }}$, displayed higher resistance to hydrogen peroxide (Supplementary Fig. S2C) compared with the wild-type strain. This effect was not observed in $X c c^{\text {AWAdA }}$ or $X c c^{\text {AWAdB }}$ (Supplementary Fig. S2C). All three adapted strains displayed reduced motility on soft nutrient agar (NA) compared with the wild-type strain (Fig. 3E).

We tested the expression of selected T3SS-associated genes (T3SS regulator $h r p X$; T3SS structural gene $h r p F$; and T3SS effector encoding genes avrGf1, xopN, and xopAU; the housekeeping gene gyrA was used as a control) in XVM2 medium using $\beta$-glucuronidase (GUS) promoter fusions. The GUS activity of three $(h r p F, a v r G f 1$, and $x o p A U)$ of the six tested genes was

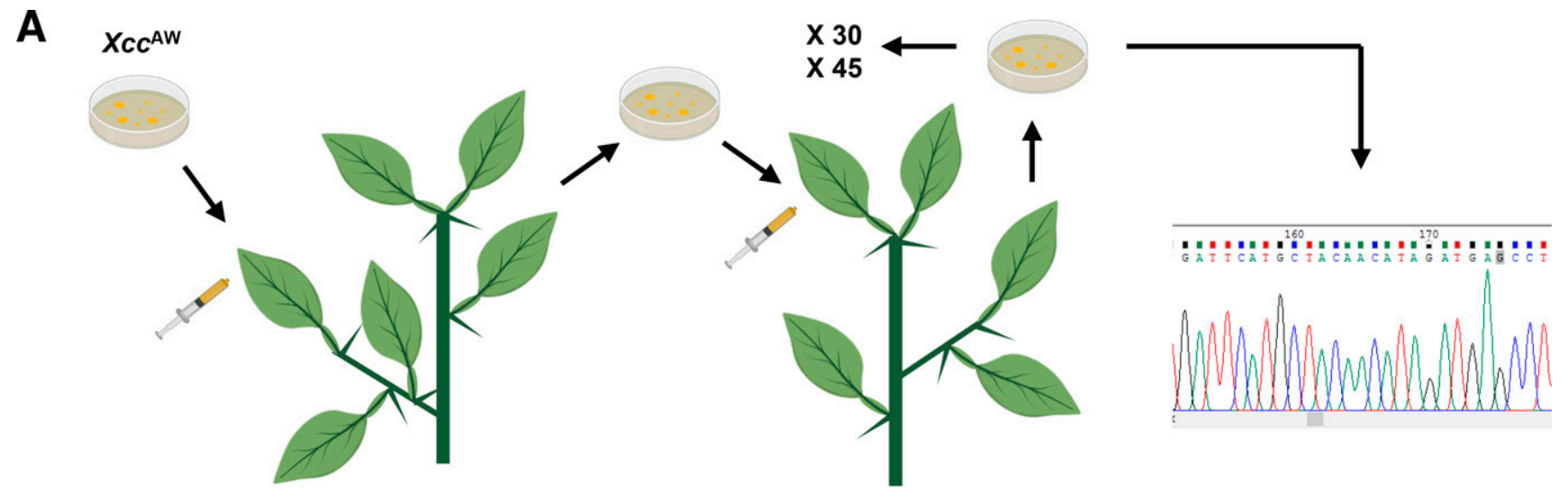

B
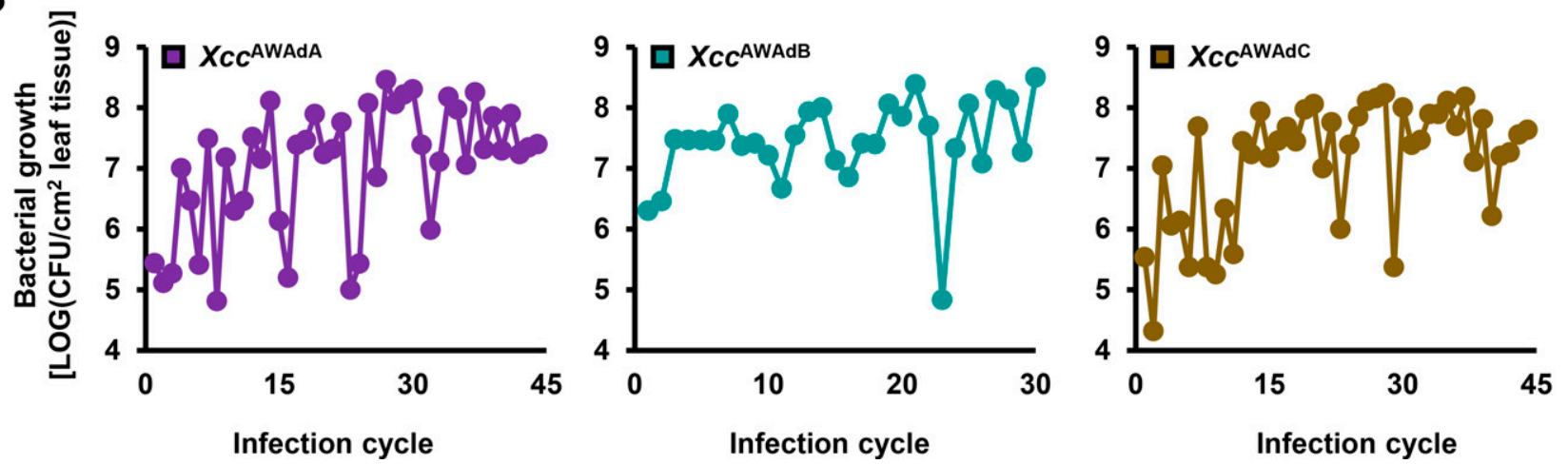

Fig. 2. Experimental evolution of Xanthomonas citri subsp. citri strain AW $\left(X c c^{\mathrm{AW}}\right)$ adaptation to sweet orange. A, The scheme represents the experimental evolution of $X c c^{\mathrm{AW}}$ adaptation to sweet orange. The experiment was conducted in parallel with three strains. The scheme was prepared with BioRender. B, Sweet orange leaves were syringe infiltrated with suspensions $\left(5 \times 10^{5} \mathrm{CFU} / \mathrm{ml}\right)$ of $X c c^{\mathrm{AW}}$. Bacteria were isolated 7 to 10 days after inoculation, and isolated cultures were used as inoculum for the next infection for the duration of 30 to 45 cycles. Graphs represent in planta bacterial populations at the time of extraction at each infection cycle. 
significantly elevated in all three adapted strains compared with the wild-type strain (Fig. 3F). Our analyses showed that motility, resistance to hydrogen peroxide, and expression of T3SS genes and T3SS effector genes were altered during the adaptation of $X c c^{\mathrm{AW}}$ strains, which suggests that these traits probably play a role in host adaptation.

Mutations identified in adapted $X c c^{\mathrm{AW}}$ strains.

To identify genetic mutations that enhance fitness in sweet orange, we sequenced the genomes of the three adapted $X c c^{\mathrm{AW}}$ strains. As a control, we resequenced the genome sequence of the wild-type strain. We compared the genomes of the three adapted strains with that of the wild-type strain and validated mutations by PCR and Sanger sequencing. The validated genetic mutations identified in each of the strains are listed in Table 1. Our analysis identified a small number of point mutations or short insertions or deletions in each strain. The assembled genomes of the adapted $X c c^{\mathrm{AW}}$ strains revealed mutations in the central repeat array of the TALE pthAW1. Intriguingly, repeat 19, which harbored a repeat variable diresidue (RVD) of NS, was deleted in PthAW1 ${ }^{\text {AWAdA }}$ (Fig. 4A). The repeat array of PthAW1 ${ }^{\text {AWAdC }}$ harbored a deletion of the first two repeats, containing NI and $\mathrm{N}^{*}$ RVDs (Fig. 4A). Sanger sequencing validated both deletion events as occurring in the adapted variants and not in the original $p t h A W 1$. All three strains harbored an additional repeat containing an NI RVD at position 10 in the repeat array (Fig. 4A). Because identical adaptation of all pthAWI homologs is unlikely to occur independently, we determined the sequence of pthAWl in the wild-type Xcaw12879 strain $\left(X_{c c}{ }^{\mathrm{AW}}\right)$ (NCBI accession number MW147138) and confirmed that the additional NI at position 10 was present in the original strain prior to adaptation. It is unknown whether the bacteria acquired an additional repeat prior to the experiment or whether an assembly error occurred in the original genome sequence deposit of Xcaw12879 $\left(X c c^{\mathrm{AW}}\right)$. We also
A

Sweet orange

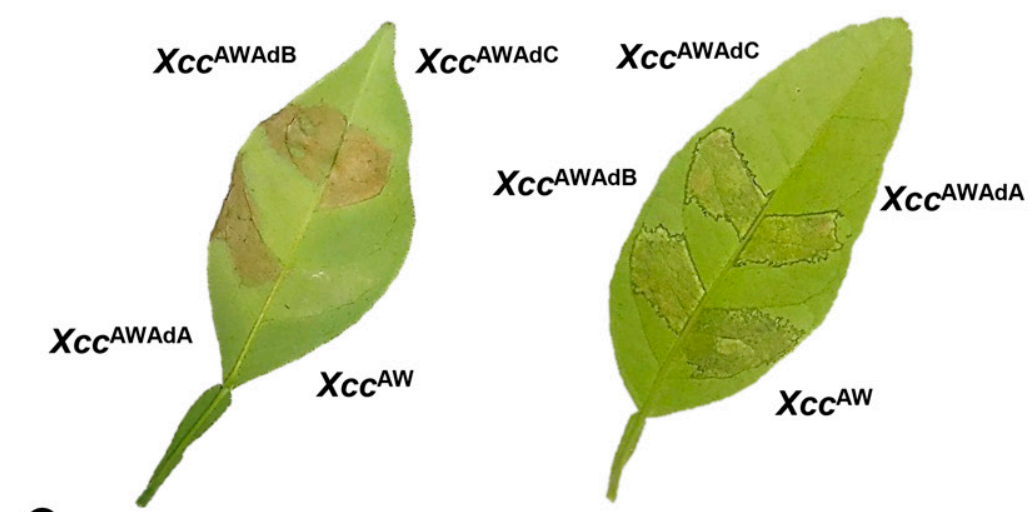

C

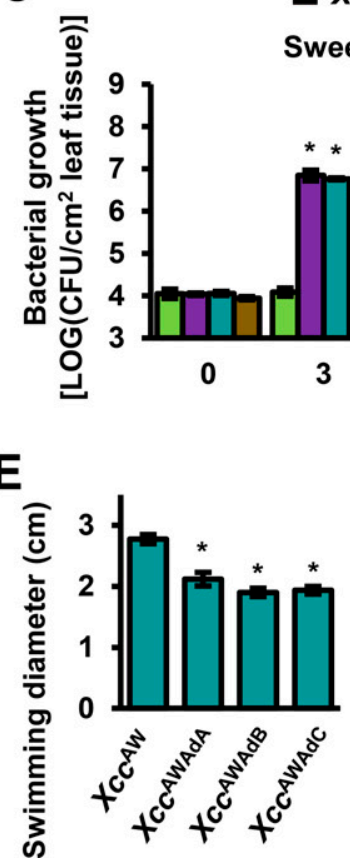

Key lime

$X c c^{A W} \square X c c^{A W A d A} \square X c c^{A W A d B} \square X c c^{A W A d C}$ weet orange

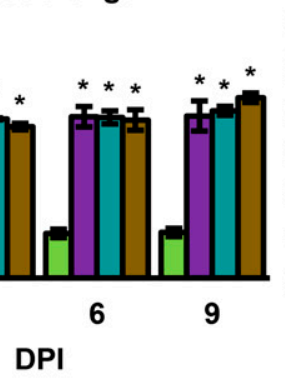

$\mathbf{F}$
B

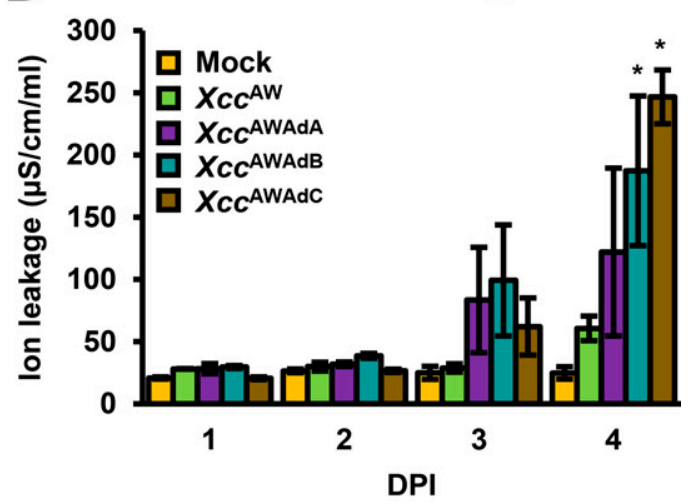

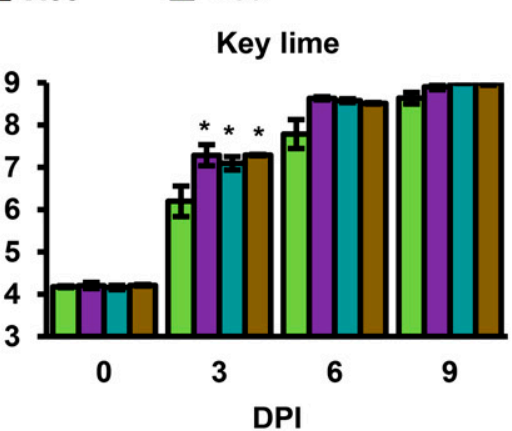

D
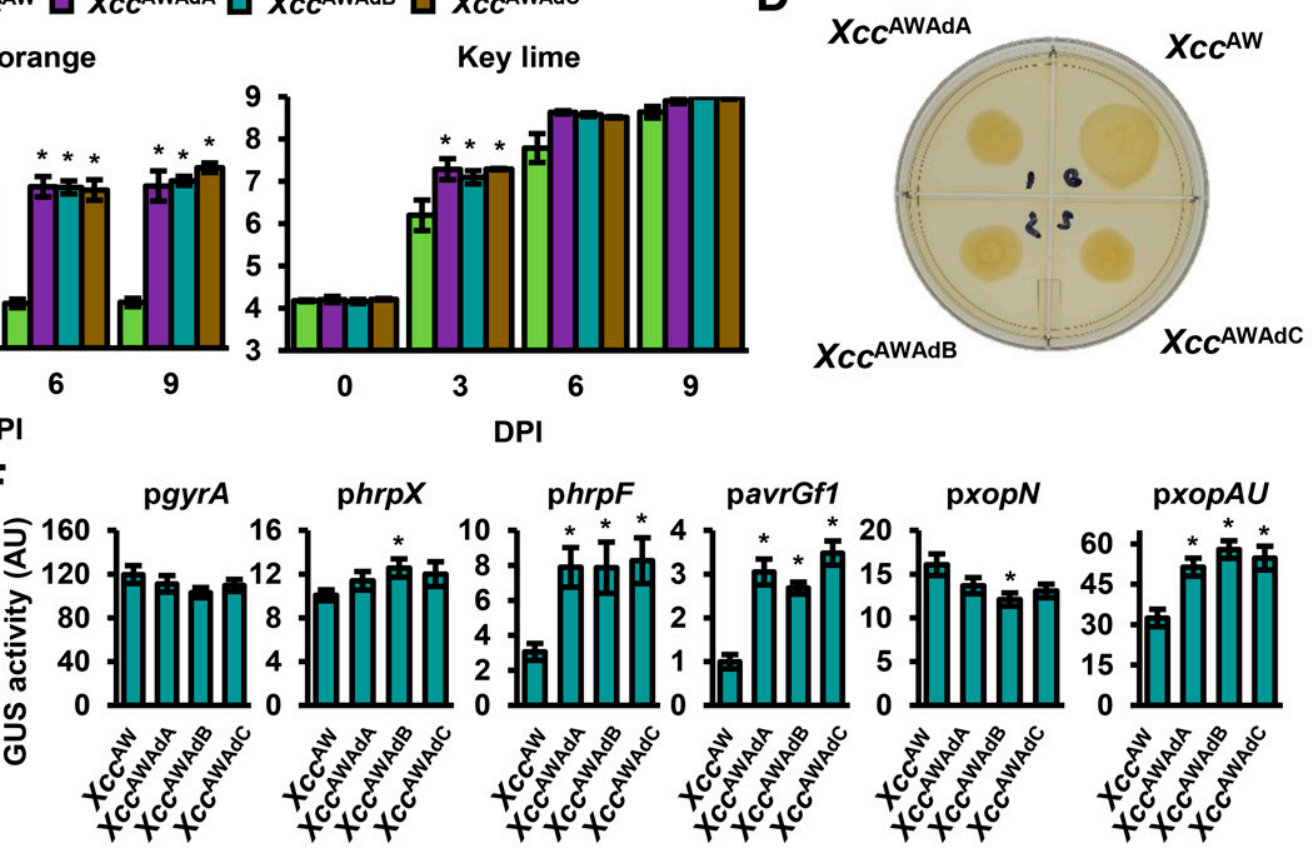

pxopN

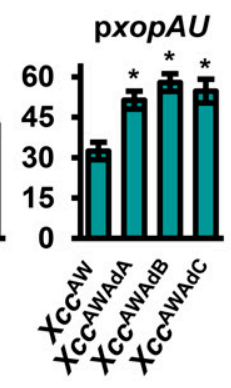

Fig. 3. Adapted Xanthomonas citri subsp. citri strain $\mathrm{AW}\left(X c c^{\mathrm{AW}}\right)$ strains display altered virulence and induce stronger hypersensitive response. A to $\mathbf{C}$, Wild-type and adapted $X c c^{\mathrm{AW}}$ cultures $\left(10^{8} \mathrm{CFU} / \mathrm{ml}\right.$ for A and B, $10^{6} \mathrm{CFU} / \mathrm{ml}$ for C) were syringe inoculated into sweet orange and key lime leaves. A, Pictures were taken 7 days postinoculation (DPI). B, Cell death was quantified by ion leakage on the indicated DPI. (C) In planta bacterial populations were monitored on the indicated days postinoculation. D and E, Motility assay. Cultures were spotted on soft (0.4\% agar) nutrient agar plates. D, Pictures were taken 3 days after spotting. E, Colony diameter was measured 3 days after spotting. F, Promoter activity of the indicated genes was quantified in wildtype and adapted $X c c^{\mathrm{AW}}$ strains grown in XVM2 with the $\beta$-glucuronidase (GUS) reporter gene. B, C, E, and $\mathbf{F}$, Data are means \pm standard error of at least three biological replicates. Asterisks indicate significant differences $(P<0.05$, Student's $t$ test $)$ compared with wild-type $X c c^{\mathrm{AW}}$. All experiments were repeated at least three times, with similar results. 
evaluated the expression of $p t h A W 1$ in NB, XVM2, and in planta. pthAW1 expression was significantly higher in XVM2 and in planta (Supplementary Fig. S3).

In addition to $p t h A W 1$, numerous other mutations were identified in the three adapted strains. $X c c^{\mathrm{AWAdA}}$ and $X c c^{\mathrm{AWAdB}}$ harbored a single nucleotide deletion in $X C A W \_01908$, which resulted in a frame shift (Table 1). The largest number of mutations was identified in $X c c^{\text {AWAdC }}$. Point mutations that resulted in amino substitutions were identified in the general secretory pathway protein SecD-coding gene (XCAW_02188) (Driessen et al. 1998) and transfer RNA uridine 5-carboxymethylaminomethyl modification protein GidA-coding gene (XCAW_00784) (Table 1) (Yim et al. 2006). Permease-coding gene $X C A W \_00056$ harbored two nucleotide insertions that disrupted the coding frame (Table 1). In addition, deletions or insertions of 7 to 24 repetitive DNA motifs were identified in the putative regulatory $5^{\prime}$ cis-element of hypothetical protein, ATP-binding protein, and TonB receptor-coding genes (XCAW_03398, XCAW_03891, and XCAW_04666).
pthAW1 inhibits canker development in sweet orange.

Our genome analysis revealed that two adapted $X c c^{\mathrm{AW}}$ strains had independent repeat deletions in the TALE PthAW1. TALEs are Avr effectors in resistant varieties in a multitude of pathosystems (Ji et al. 2016; Roeschlin et al. 2019; Schornack et al. 2004; J. Zhang et al. 2015). Therefore, we hypothesized that $p t h A W 1$ might function as an $a v r$ gene in sweet orange. To examine this hypothesis, we introduced pthAWl homologs from the wild-type and adapted $X c c^{\mathrm{AW}}$ strains $\left(X c c^{\mathrm{AWAdA}}\right.$ and $\left.X c c^{\mathrm{AWAdC}}\right)$ into sweetorange-pathogenic strain $X c c^{\mathrm{A}}$ and tested pathogenesis in sweet orange and key lime. Introduction of the wild type but not the adapted pthAWI ( $p$ thAWI ${ }^{\text {AdA }}$ and $p t h A W 1^{\text {AdC }}$ ) into $X c c^{\mathrm{A}}$ suppressed the development of canker symptoms in sweet orange (Fig. 4B), and bacterial populations were reduced by approximately 100-fold compared with $X c c^{\mathrm{A}}$ (Fig. 4C). PthAW1 and its variants did not significantly affect the development of symptoms or bacterial growth in key lime (Fig. 4B and 4C). Additionally, introduction of the wild-type pthAWI into the adapted strains $X c c^{\mathrm{AWAdA}}, X c c^{\mathrm{AWAdB}}$, and $X c c^{\mathrm{AWAdC}}$ reduced bacterial growth

Table 1. Validated mutations in the adapted Xanthomonas citri subsp. citri AW $\left(X c c^{\mathrm{aW}}\right)$ strains

\begin{tabular}{|c|c|c|c|c|c|}
\hline Site $^{\mathrm{a}}$ & Type $^{\text {b }}$ & Annotation & Position & Mutation & Outcome \\
\hline \multicolumn{6}{|l|}{$X c c^{\mathrm{aWadA}}$} \\
\hline \multicolumn{6}{|l|}{ Genome } \\
\hline XCAW_01908 & D1 & Hypothetical protein & $2,119,649$ & $\begin{array}{l}\text { GGGGGGGGGG } \\
\text { GCGCAC } \\
\text { >GGGGGGGGGG } \\
\text { CGCAC }\end{array}$ & Frame shift after H16 \\
\hline $\mathrm{NC}$ & D40 & $\begin{array}{l}\text { Intragenic region between } \\
\text { XCAW_03958 (OMP) and } \\
\text { XCAW_03959 (porphobilinogen } \\
\text { deaminase) }\end{array}$ & $\begin{array}{c}4,432,925-4 \\
432,966\end{array}$ & $\begin{array}{l}\text { GCGACAGGCG } \\
\text { TTCCCGGG } \\
\text { AACGCCTGTCG } \\
\text { CGGCCGGGGCC }\end{array}$ & \\
\hline \multicolumn{6}{|l|}{ pXcaw58 } \\
\hline XCAW_b00018 & D105 & pthAW1 & $15,274-15,378$ & $\begin{array}{l}\text { CAGGCGCT ... TAG } \\
\text { CGGTGGCAAGCAG }\end{array}$ & $\begin{array}{l}\Delta \mathrm{G} 843-\mathrm{S} 875, \text { deletion of } \\
\text { repeat } 19(\mathrm{NS})\end{array}$ \\
\hline \multicolumn{6}{|l|}{$X c c^{\mathrm{aWadB}}$} \\
\hline XCAW_01908 & D1 & Hypothetical protein & $2,119,649$ & $\begin{array}{l}\text { GGGGGGGGG } \\
\text { GGCGCAC } \\
>\text { GGGGGGGGGG } \\
\text { CGCAC }\end{array}$ & Frame shift after $\mathrm{H} 16$ \\
\hline $\mathrm{NC}$ & SNP & $\begin{array}{l}\text { Intragenic region between } \\
\text { XCAW_01880 (fliK) and } \\
\text { XCAW_01881 (fliL) }\end{array}$ & $2,089,368$ & $\mathrm{~T}->\mathrm{G}$ & \\
\hline \multicolumn{6}{|l|}{$X c c^{\mathrm{aWadC}}$} \\
\hline \multicolumn{6}{|l|}{ Genome } \\
\hline XCAW_00056 & $\mathrm{I} 2$ & $\begin{array}{l}\text { Permeases of the major } \\
\text { facilitator superfamily }\end{array}$ & $\begin{array}{l}62,039 \\
62,063\end{array}$ & $\begin{array}{l}\text { GTT-GGGCTGCGCGCC } \\
\text { GGCCTGGATGCC } \\
\text { GGGC-> } \\
\text { GTTGGGGC } \\
\text { TGCGCGC } \\
\text { CGGCCTGGAT } \\
\text { GCCGGGGC }\end{array}$ & Frame shift after G226 \\
\hline XCAW_00784 & SNP & $\begin{array}{l}\text { tRNA uridine 5-carboxy- } \\
\text { methylaminomethyl }\end{array}$ & 911,939 & $\mathrm{G}->\mathrm{A}$ & P117L \\
\hline XCAW_02188 & SNP & Preprotein translocase subunit SecD & $2,421,072$ & $\mathrm{~A}->\mathrm{G}$ & V283A \\
\hline $\mathrm{NC}$ & D7 & $\begin{array}{l}\text { Intragenic region (possible promoter) } \\
\text { between XCAW_03398 and } \\
\text { XCAW_03399(spoT) }\end{array}$ & $\begin{array}{c}3,804,466-3 \\
804,472\end{array}$ & GGAATCG & \\
\hline $\mathrm{NC}$ & D7 & $\begin{array}{l}\text { Intragenic region (possible promoter) } \\
\text { between XCAW_03890 and } \\
\text { XCAW_03891(tonB) }\end{array}$ & $\begin{array}{c}4,352,509-4 \\
352,515\end{array}$ & CGTTGGC & \\
\hline $\mathrm{NC}$ & $\mathrm{I} 24$ & $\begin{array}{l}\text { Intragenic region (possible promoter) } \\
\text { between XCAW_04666(ATP- } \\
\text { binding protein) and } \\
\text { XCAW_04667 }\end{array}$ & $5,231,522$ & $\begin{array}{l}\text { TTGCTGTTGCTGT } \\
\text { TGCTGTTGCTG }\end{array}$ & \\
\hline \multicolumn{6}{|l|}{ pXcaw58 } \\
\hline XCAW_b00018 & D201 & pthAW1 & $13,615-13,815$ & $\begin{array}{l}\text { CAGGTGGTG ... GGCCTG } \\
\text { ACCCCGGCA }\end{array}$ & $\begin{array}{l}\Delta \mathrm{Q} 293-\mathrm{A} 359, \text { deletion } \\
\quad \text { of repeats } 1(\mathrm{NI})+2\left(\mathrm{~N}^{*}\right)\end{array}$ \\
\hline
\end{tabular}

\footnotetext{
${ }^{\mathrm{a}} \mathrm{NC}=$ noncoding.

${ }^{\mathrm{b}} \mathrm{D}=$ deletion, $\mathrm{SNP}=$ single-nucleotide polymorphism, and $\mathrm{I}=$ insertion.
} 
(Fig. 5A) and also abolished the HR phenotypes on Valencia sweet orange (Fig. 5B).

Next, we deleted pthAWl in $X c c^{\mathrm{AW}}$ and $X c c^{\mathrm{AW}} \Delta a v r G f 1$ and inoculated bacteria into sweet orange and key lime. Neither symptoms nor bacterial growth were significantly altered between the strains in either variety (Supplementary Fig. S4), which suggests that disrupting pthAWl is not sufficient to alter the host range of $X c c^{\mathrm{AW}}$.

Our results show that $p t h A W 1$ significantly affects the ability of $X$. citri subsp. citri to colonize and promote canker symptoms in sweet orange. Thus, pthAWl might be involved in determining the host specificity of $X c c^{\mathrm{AW}}$.

PthAW1 induces ion leakage and expression of pathogenesis-related genes but has no effect on expression of $C S L O B 1$.

We hypothesized that PthAW1 inhibition of canker development in sweet orange results from induction of host immune responses. To test this hypothesis, we measured its effect on ion leakage and expression of pathogenesis-related $(P R)$ genes and canker-susceptibility gene CsLOB1. AvrGf1 was included for comparison purposes.

The HR induced by different Xanthomonas strains was quantified by measuring the ion leakage. The ion leakage induced by $X c c^{\mathrm{A}}, X c c^{\mathrm{AW}}, X c c^{\mathrm{AW}} \Delta a v r G f 1$, and $X c c^{\mathrm{A}}\left(\operatorname{avrGf1_{AW}}\right)$ strains on fully expanded young leaves of Valencia sweet orange was quantified at 3 and 6 DPI. At 3 DPI, $X c c^{\mathrm{AW}}$ infiltrated leaves exhibited approximately 2- and 2.5-fold higher ion leakage than leaves infiltrated with $X c c^{\mathrm{AW}} \Delta a v r G f 1$ and $X c c^{\mathrm{A}}$ strains, respectively (Fig. 6A). Similarly, $X c c^{A}\left(\operatorname{avrGf1_{AW}}\right)$ strain induced approximately 11- and 14-fold higher ion leakage than $X c c^{\mathrm{AW}} \Delta a v r G f 1$ and $X c c^{\mathrm{A}}$, respectively (Fig. 6A). At $6 \mathrm{DPI}$, all of the strains induced higher ion leakage in the infiltrated leaves than that at 3 DPI. $X c c^{\mathrm{AW}}$ induced approximately twofold higher ion leakage than $X c c^{\mathrm{AW}} \Delta a v r G f 1$ and $X c c^{\mathrm{A}}$ strains (Fig. 6A). Similarly, $X c c^{\mathrm{A}}\left(a v r G f 1_{A W}\right)$ induced approximately fourfold higher ion leakage than $X c c^{\mathrm{AW}} \Delta a v r G f 1$ and $X c c^{\mathrm{A}}$ strains (Fig. 6A).

In another ion leakage experiment, at 3 DPI, $X c c^{\mathrm{A}}\left(p t h A W 1_{A W}\right)$ and $\operatorname{Xcc}^{\mathrm{A}}\left(a v r G f 1_{A W}\right)$ induced approximately 2- and 11-fold higher ion leakage, respectively, than the wild-type strain $X c c^{\mathrm{A}}$ (Fig. 6B).

A

RVD

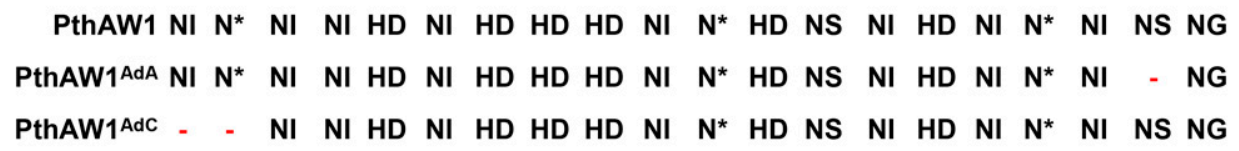

B
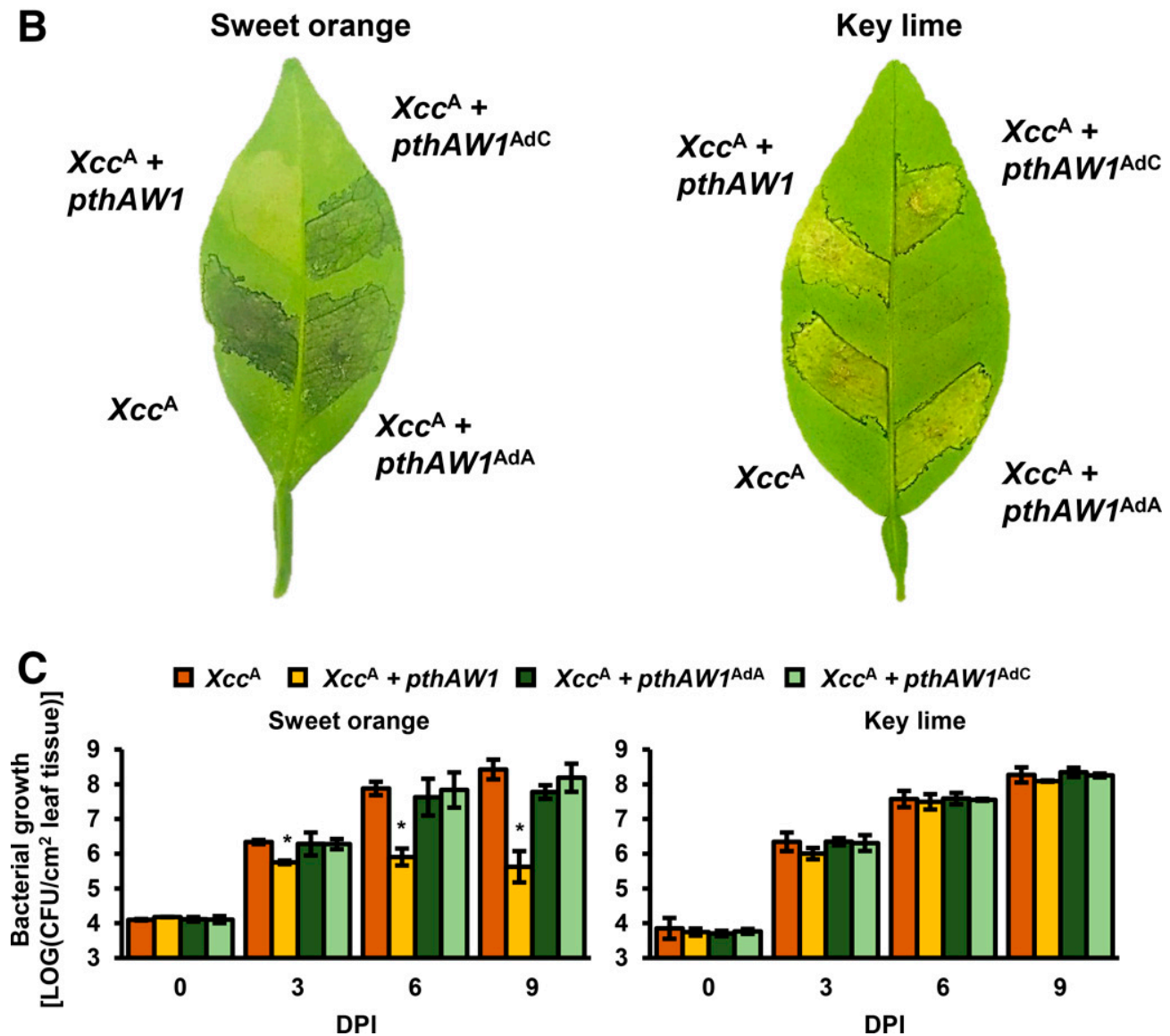

Fig. 4. Repeat arrays of PthAW1 are altered in the adapted Xanthomonas citri subsp. citri strain AW $\left(X c c^{\mathrm{AW}}\right)$ strains. A, Repeat variable diresidues (RVDs) of the central repeat array of PthAW1 of wild-type and adapted $X c c^{\mathrm{AW}}$ strains. Red hyphen indicates deletion of repeat. B and $\mathbf{C}, X c c^{\mathrm{A}}$ cultures $\left(10^{8} \mathrm{CFU} / \mathrm{ml}\right.$ for B and $10^{6} \mathrm{CFU} / \mathrm{ml}$ for $\mathrm{C}$ ) carrying the indicated PthAW1 wild-type and variants were syringe inoculated into sweet orange and key lime leaves. B, Pictures were taken 7 days postinoculation (DPI). C, Bacterial populations were determined at the indicated days postinoculation. Data are means \pm standard error of three biological replicates. Asterisks indicate significant differences $(P<0.05$, Student's $t$ test $)$ compared with $X c c^{\mathrm{A}}$. Experiments were repeated at least three times, with similar results. 
Similarly, $X c c^{\mathrm{A}}\left(p t h A W 1_{A W}\right)$ and $X c c^{\mathrm{A}}\left(a v r G f 1_{A W}\right)$ induced approximately two- and fivefold higher ion leakage, respectively, than the wild-type strain $X c c^{\mathrm{A}}$ at 6 DPI (Fig. 6B).

Next, the impact of $a v r G f 1$ and pthAWl on the expression of $P R$ genes was analyzed using reverse-transcription quantitative PCR. $X c c^{\mathrm{A}}, X c c^{\mathrm{AW}}, X c c^{\mathrm{AW}} \Delta a v r G f 1$, and $X c c^{\mathrm{A}}\left(a v r G f 1_{A W}\right)$ strains were infiltrated into fully expanded young leaves of Valencia sweet orange. Both $X c c^{\mathrm{AW}}$ and $X c c^{\mathrm{A}}\left(\operatorname{avrGf1_{AW})}\right.$ induced the expression of $P R 1$ and $P R 2$ genes at 48 or $72 \mathrm{~h}$ post inoculation (Fig. 7A and B). Mutation of avrGfl (Xcc $\left.{ }^{\mathrm{AW}} \Delta a v r G f 1\right)$ significantly decreased the expression of $P R 1$ and $P R 2$ genes compared with $X c c^{\mathrm{AW}}$ (Fig. 7A and B).

In another experiment, $X c c^{\mathrm{A}}\left(\operatorname{avr} G f 1_{A W}\right)$ and $X c c^{\mathrm{A}}\left(p t h A W 1_{A W}\right)$ significantly induced the expression of $P R 1, P R 2$, and $P R 3$ genes at 48 or $72 \mathrm{~h}$ postinoculation (Fig. 7C and D) but had no effect on the expression of $C S L O B 1$ (Fig. 7E) compared with the wild-type $X c c^{\mathrm{A}}$ strain.

\section{Citrus varieties display differential responses to AvrGf1 and PthAW1.}

$X c c^{\mathrm{AW}}$ strains display a very narrow host range and almost solely infect lime and alemow (Sun et al. 2004). However, the determinants of the host specificity of $X c c^{\mathrm{AW}}$ have not been characterized in any variety besides grapefruit and sweet orange. We aimed to determine whether PthAW1 and AvrGf1, which we identified as Avr effectors in sweet orange, determine the host specificity of $X c c^{\mathrm{AW}}$ in other citrus varieties.

First, we examined the responses of different citrus varieties to $X c c^{\mathrm{AW}}$ and identified that $X c c^{\mathrm{AW}}$ was unable to cause canker symptoms in 10 of the 12 varieties tested (Table 2 ; Fig. 8). Hirado pomelo (Citrus maxima), which was not reported to be a host of $X c c^{\mathrm{AW}}$, was susceptible to this strain, and $X c c^{\mathrm{AW}}$ caused canker symptoms and colonized this plant to approximately $10^{8} \mathrm{CFU} /$ $\mathrm{cm}^{2}$ of leaf tissue (Table 2; Fig. 8; Supplementary Fig. S5).

Next, we examined the responses of different citrus varieties to $X c c^{\mathrm{A}}$ carrying either $a v r G f 1$ or $p t h A W 1$. AvrGf1 elicited HR in 7 of 12 varieties tested (W. Murcott mandarin, Nules clementine, Sugar Bell tangerine, Valencia sweet orange, Duncan grapefruit, sour orange, and Eureka lemon) (Fig. 8). PthAW1 abolished canker development in only 3 of the 12 varieties tested (Valencia sweet orange, Nules clementine, and Meyer lemon) (Table 2; Fig. 8). It is intriguing that neither PthAW1 nor AvrGf1 suppressed the formation of canker pustules by $X c c^{\mathrm{A}}$ in the Cleopatra and Dancy mandarins that are resistant to $X c c^{\mathrm{AW}}$. This suggests that these two effectors are not the only factors that determine the host specificity of $X c c^{\mathrm{AW}}$ in citrus.

Our data indicate that the host specificity of $X c c^{\mathrm{AW}}$ is likely determined by multiple $R$ genes that are not universally distributed in citrus varieties. Our results also suggest that other factors in addition to those responsible for recognition of AvrGf1 and PthAW1 play a role in immunity to $X c c^{\mathrm{AW}}$ in at least some of the resistant citrus varieties.

\section{DISCUSSION}

This study utilized an experimental evolution approach to evaluate how xanthomonads evolve in incompatible hosts and identify genes that play a role in their adaptation. We used $X c c^{\mathrm{AW}}$, which

A

in planta growth assay
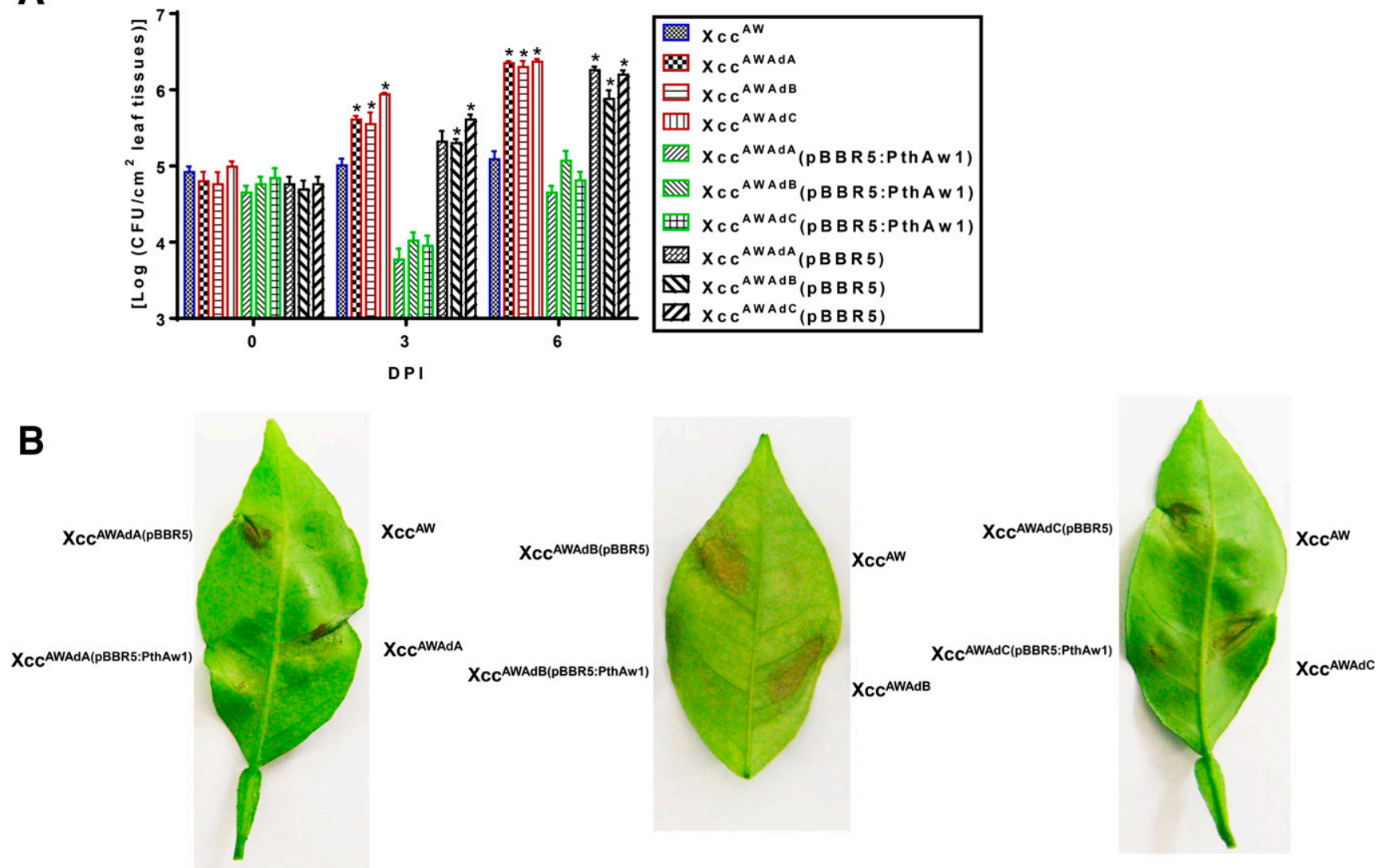

Fig. 5. Overexpression of pthAW1 in the adapted strains of Xanthomonas citri subsp. citri strain AW (Xcc $\left.{ }^{\mathrm{AW}}\right)$ suppresses their growth and hypersensitive response induction in Valencia sweet orange. A, In planta (Valencia sweet orange) growth analysis of wild-type Xcc ${ }^{\mathrm{AW}}$, adapted strains (Xcc ${ }^{\mathrm{AWAdA}}$ $X c c^{\text {AWAdB }}$, and $\left.X c c^{\text {AWAdC }}\right)$, adapted strains harboring PthAW1 from wild-type $\left(X c c^{\text {AWAdA }}\right.$ [pBRR5:PthAW1], Xcc ${ }^{\text {AWAdB }}$ [pBRR5:PthAW1], and $X c c^{\text {AWAdC }}$ [pBRR5:PthAW1]), and empty vector $\left(X c c^{\text {AWAdA }}\right.$ [pBRR5], Xcc ${ }^{\text {AWAdB }}$ [pBRR5], and $X c c^{\text {AWAdC }}$ [pBRR5]) after syringe inoculation $\left(2.5 \times 10^{8}\right.$ CFU/ml). The asterisk shows a statistically significant difference compared with the wild-type strain at the same days postinoculation (DPI) $(P<0.05$, data shown are mean \pm standard error, $n=4)$. The experiment was repeated twice, with similar results. B, Symptom analysis at 6 DPI. 
has a narrow host range that includes lime and alemow but not sweet orange, as a model. $X c c^{\mathrm{AW}}$ shares high genomic sequence homology with $X c c^{\mathrm{A}}$ (Jalan et al. 2013a), which can cause disease in almost all commercial varieties of citrus. Intriguingly, we identified PthAW1 as another Avr effector that restricts the host range of $X$. citri subsp. citri, in addition to AvrGf1 (Rybak et al. 2009). PthAW1 is a typical TALE. TALEs are abundant in Xanthomonas spp., and specific TALEs are important virulence factors in many Xanthomonas spp. (Perez-Quintero and Szurek 2019). Unlike other type III effectors, which share similar functions in different hosts, TALEs are extremely specific. The TALE repeat array dictates the affinity of each TALE to a DNA sequence of an effectorbinding element (EBE) in the promoter of host susceptibility genes (Doyle et al. 2013). The DNA sequence of each EBE is unique to a promoter in specific plant species or varieties and, therefore, the contribution of each TALE to virulence is host dependent. TALEs also restrict the host range by recognition of the TALE by the host immune system by either an NBS-LRR-resistant gene or the binding to the EBE of an executor-resistant gene (Hutin et al. 2015; J. Zhang et al. 2015). In citrus, $\mathrm{PthA} 4^{\mathrm{AT}}$ of the $X c c^{\mathrm{AT}}$ strain promotes host-specific immune responses that limit the host range of the bacterium, which indicates that TALEs control the host range of X. citri subsp. citri as well (Roeschlin et al. 2019). Intriguingly, PthA4 is involved in immunity of Meiwa kumquat against $X c c^{\mathrm{A}}$ via inducing the known canker susceptibility gene CsLOB1 (Teper et al. 2020), whereas PthAW1 triggers immune responses in sweet orange independent of $C S L O B 1$.

Strain $X c c^{\mathrm{AW}}$ encodes two unique TALEs: PthAW1 and PthAW2 (Jalan et al. 2013a). PthAW2 shares functional similarity with the $X c c^{\mathrm{A}}$ effector PthA4, which induces expression of the CSLOBI susceptibility gene to promote canker symptoms, and complements the $\mathrm{Xcc}^{\mathrm{A}}$ pthA4 mutant (Hu et al. 2014). The
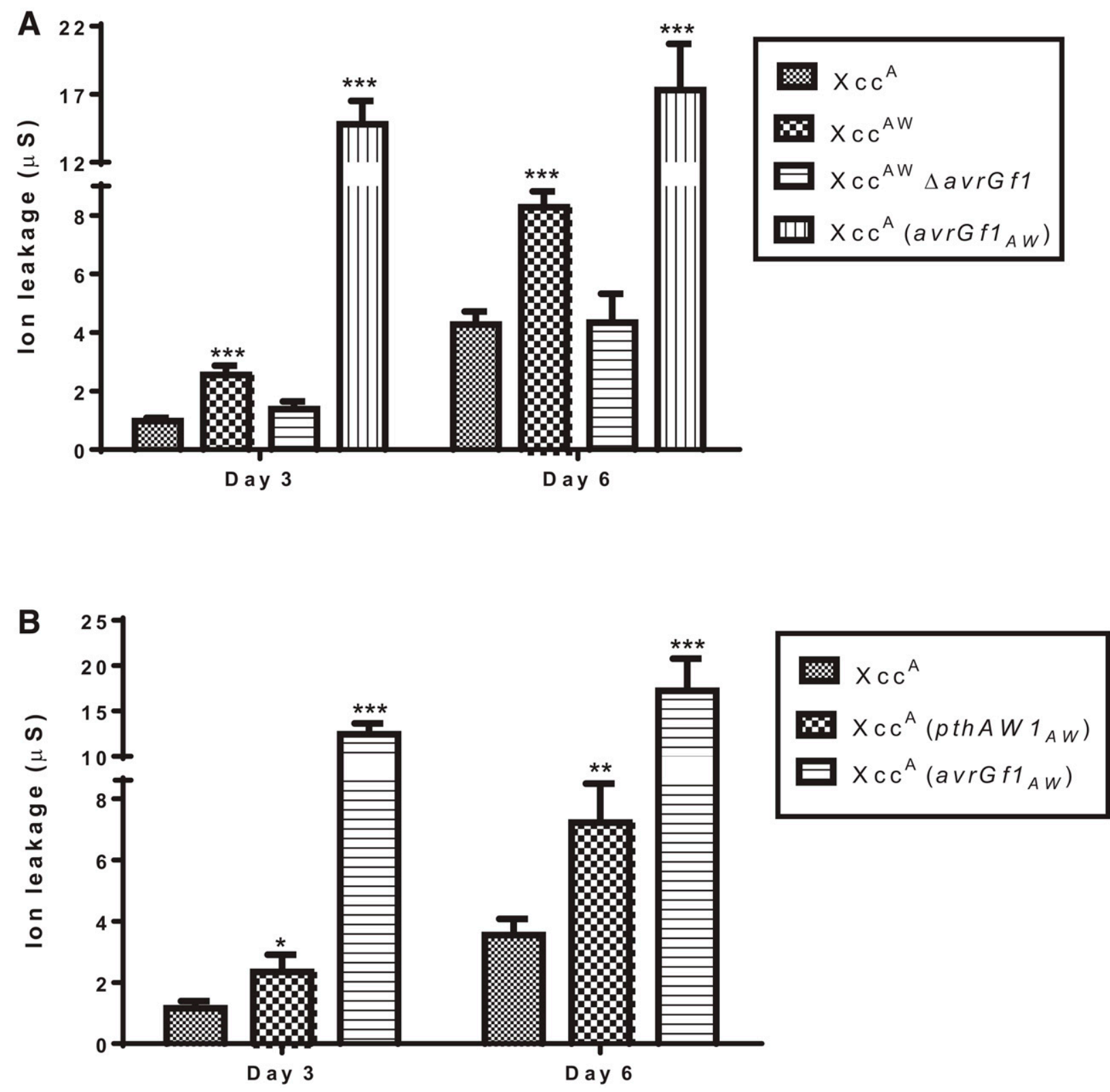

Fig. 6. AvrGf1 and PthAW1 induce ion leakage on Valencia sweet orange leaves. A, Cultures of Xanthomonas citri subsp. $c^{\text {itri }}$ strains Xcc ${ }^{\mathrm{A}}$, Xcc ${ }^{\mathrm{AW}}$, $X c c^{\mathrm{AW}} \Delta a v r G f 1$, and $X c c^{\mathrm{A}}\left(a v r G f 1_{A W}\right)$ at $1.0 \times 10^{8} \mathrm{CFU} / \mathrm{ml}$ were infiltrated into fully expanded young leaves of Valencia sweet orange. Ion leakage was

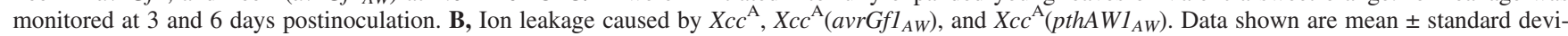
ation ( $n=4$ plants). Experiments were repeated four times with similar results. Asterisks *, **, and *** indicate $P$ value $\leq 0.05,0.01$, and 0.001 , respectively, for induced ion leakage compared with $X c c^{\mathrm{A}}$. 
contribution of PthAW1 to virulence has yet to be identified, and the plant genes targeted by the effector remain unknown. Two independent adapted strains identified during our study displayed deletions in the repeat array of PthAW1. Introduction of pthAWI from $X c c^{\mathrm{AW}}$ but not the adaptive variants into the broad citrus host range strain $X c c^{\mathrm{A}}$ abolished its ability to colonize and cause canker symptoms in sweet orange. The data demonstrate that pthAWI functions as an $a v r$ gene in sweet orange and possibly plays a partial role in the determination of the host range of $X c c^{\mathrm{AW}}$ strains. How PthAW1 triggers immunity in sweet orange remains unknown. The narrow range of PthAW1-resistant varieties and the significant effect of a single repeat deletion on its Avr functions
A
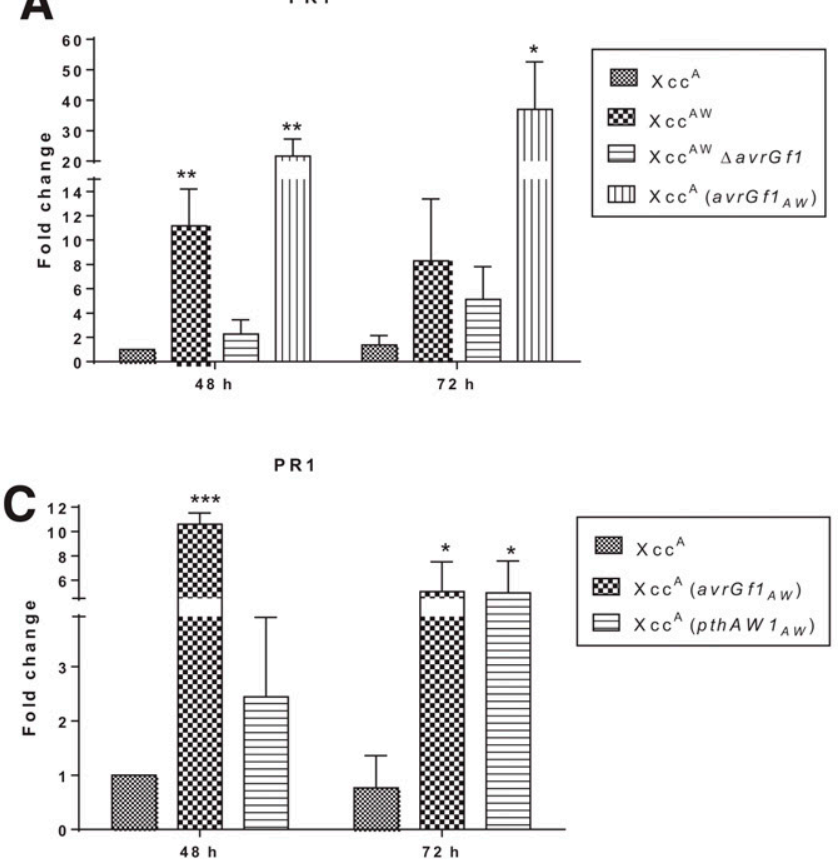

E

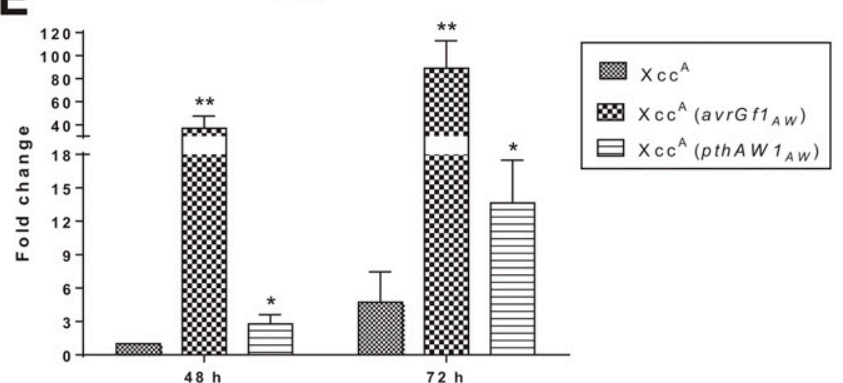

B

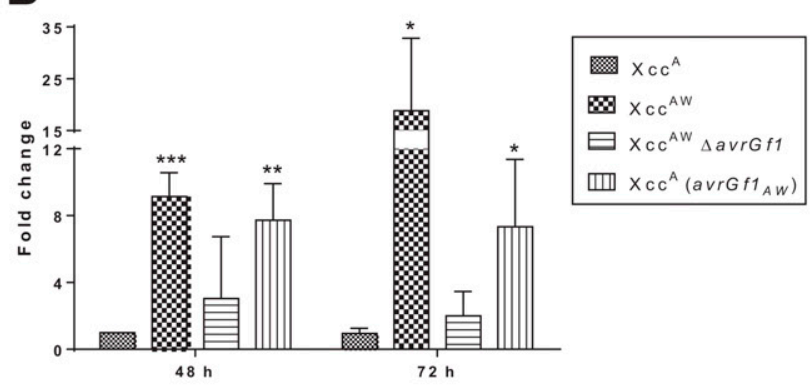

PR2

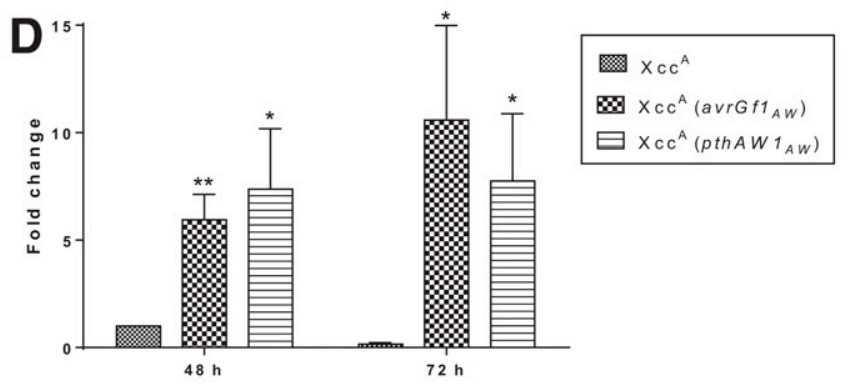

$\mathbf{F}$

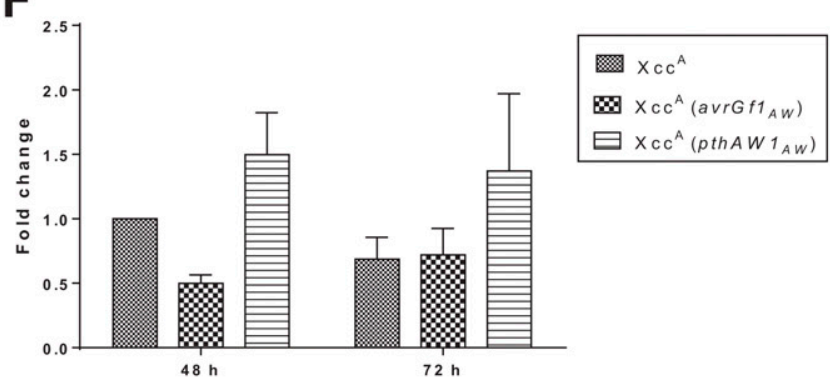

Fig. 7. AvrGf1 and PthAW1 induce expression of pathogenesis-related $(P R)$ genes on Valencia sweet orange leaves. Reverse-transcription quantitative PCR assays were conducted to measure the expression of $\mathbf{A}, P R 1$ and $\mathbf{B}, P R 2$ genes in fully expanded leaves of Valencia sweet orange infiltrated with Xanthomonas citri subsp. citri strains $X c c^{\mathrm{A}}, X c c^{\mathrm{AW}}, X c c^{\mathrm{AW}} \Delta a v r G f 1$, and $X c c^{\mathrm{A}}\left(\operatorname{avrGf1}_{A W}\right)$ at $1.0 \times 10^{8} \mathrm{CFU} / \mathrm{ml}$. Expression analyses of C, PR1; D, PR2; E, PR3; and $\mathbf{F}, C s L O B 1$ genes in Valencia sweet orange leaves infiltrated with $X c c^{\mathrm{A}}, X_{c c}^{\mathrm{A}}$ harboring $a v r G f 1_{A W},\left(X c c^{\mathrm{A}}\left[a v r G f 1_{A W}\right]\right)$, and $p t h A W 1_{A W}\left(X c c^{\mathrm{A}}[p t h A-\right.$ $\left.\left.W 1_{A W}\right]\right)$ from $X c c^{\mathrm{AW}}$ wild type. Data shown are mean \pm standard deviation $(n=3$ plants). The experiment was repeated at least twice with similar results. Asterisks *, **, and *** indicate $P$ value $\leq 0.05,0.01$, and 0.001 , respectively, for induced expression compared with the $X c c^{\mathrm{A}}$ strain.

Table 2. Response of citrus varieties to Xanthomonas citri subsp. citri $^{\mathrm{a}}$

\begin{tabular}{|c|c|c|c|c|}
\hline Citrus variety & $X c c^{A W}$ & $X c c^{A}$ & $X c c^{A}+p t h A W 1$ & $X c c^{A}+\operatorname{avrGfI}$ \\
\hline Cleopatra mandarin & Chlorosis & Canker & Canker & Canker \\
\hline Dancy tangerine & Chlorosis/HR & Canker & Canker & Canker \\
\hline W. Murcott mandarin & Chlorosis/HR & Canker & Canker & HR \\
\hline Sugar Belle tangerine & HR & Canker & Canker & HR \\
\hline Nules Clementine & Chlorosis/HR & Canker & Chlorosis/HR & HR \\
\hline Valencia sweet orange & Chlorosis & Canker & Chlorosis & $\mathrm{HR}$ \\
\hline Duncan grapefruit & HR & Canker & Canker & HR \\
\hline Sour orange & HR & Canker & Canker & HR \\
\hline Hirado pomelo & Canker & Canker & Canker & Canker \\
\hline Meyer lemon & HR & Canker & Weak canker & HR \\
\hline Eureka lemon & HR & Necrotic canker & Necrotic canker & HR \\
\hline Mexican key lime & Canker & Canker & Canker & Canker \\
\hline
\end{tabular}

${ }^{\mathrm{a}} X$. citri subsp. citri strains $\mathrm{AW}\left(X c c^{\mathrm{AW}}\right)$ and $\mathrm{A}\left(X c c^{\mathrm{A}}\right) . \mathrm{HR}=$ hypersensitive response. 
suggest that target recognition may play a significant role in the Avr interaction of this effector. Therefore, it might be recognized by an executor-resistant gene or downstream of the induction of a putative target (J. Zhang et al. 2015).

The repeat structure of TALEs subjects them to constant repeat recombination and rearrangement, which enables them to adapt to novel promoters in different hosts and acquire new pathogenic traits by inducing the expression of novel target genes (PerezQuintero and Szurek 2019). Indeed, several genomic and bioinformatic studies have identified that TALE repeat arrays undergo dynamic rearrangements that occur through repeat deletions, insertions, and recombination within a single TALE and between different TALEs in the same bacteria (Denancé et al. 2018; Erkes et al. 2017). Adaptive rearrangement of repeat arrays in $L O B 1$ targeting TALEs was recently reported by our group (Teper and Wang 2021). This study further validates TALE repeat mutations by experimentally demonstrating active adaptive rearrangements in the repeat array of PthAW1, which eliminated its Avr function in sweet orange when introduced into $X c c^{\mathrm{A}}$.

All adapted $X c c^{\mathrm{AW}}$ strains were able to colonize sweet orange to a significantly greater extent than the parental $X c c^{\mathrm{AW}}$ strain. Phenotypic analysis of the adapted $X c c^{\mathrm{AW}}$ strains demonstrated that, although the three strains evolved independently of one another, they displayed similar characteristics. In addition to improved colonization of sweet orange, the three strains displayed improved colonization of susceptible key lime plants, reduced motility in soft agar plates, and enhanced the promoter activity of T3SS genes and T3SS effector genes. The acquisition of these traits by three independently adapted strains suggests that they are beneficial for colonizing the incompatible sweet orange. It is probable that these identified traits play an even more significant role in adaptation than pthAWI because the adapted strain $X c c^{\mathrm{AWAdB}}$ still colonizes the host despite not accumulating any mutations in the TALE. We do not know which genetic adaptations facilitate these phenotypes. Xcc ${ }^{\text {AWAdC }}$ harbors several point mutations in coding genes and modifications of intragenic regions that might result in altered cell physiology but these alterations are unique to $X c c^{\mathrm{A}-}$ WAdC . Furthermore, additional point mutations (other than those in Table 1) are present in genomes of adapted mutants, whose contribution to the adaption is yet to be characterized. We were not able to assemble the full genome sequences of the adapted strain and, therefore, cannot tell whether genome rearrangements occurred in these strains that might explain the observed phenotypes.

Intriguingly, all three adapted strains displayed stronger and more accelerated HR compared with the original strain. This result is counterintuitive, because most studies on hemibiotrophic pathogens such as $X$. citri subsp. citri suggest that evading the plant immune system plays a significant role in being able to cause disease and colonize the plant host (Timilsina et al. 2020; Xin et al. 2018). The enhanced HR of the adapted strains might have resulted from the increased bacterial growth in planta and the increased activity of T3SS and Avr effectors such as AvrGf1. Introduction of pthAWl into the adapted strains reduced bacterial growth and also abolished the HR in Valencia sweet orange. Taken together, our data suggest that the HR appearance is dependent on bacterial population and HR only becomes visible when pathogens reach a threshold of titer. Both AvrGf1 and PthAW1 are Avr effectors. However, it seems AvrGf1 is responsible for the HR phenotype, whereas overexpression of PthAW1 causes reduction of bacterial growth, probably resulting from immune response without causing HR. Because AvrGf1 is recognized as an Avr protein in sweet orange, we expected the avrGfl gene to be disrupted or accumulate mutations during adaptation. Unexpectedly, avrGfl was unaltered in all adapted lines. It is worth noting that T3SS and its effectors are involved in both virulence and the triggering of HR. It has yet to be determined how these traits benefit the bacteria and how the balance between the positive effect of virulent effector function and the negative effect of avirulent effector function is maintained within this system. Our experimental design creates bias toward survival at the early stages of infection because it is more likely that, at these stages, an adaptive clone could take over the population. It is possible that AvrGf1 contributes to virulence at the very early stages of the infection and is only recognized by the host immune system at the later stages and, therefore, is not likely to be altered.

Another interesting finding is that none of the adapted strains were able to induce canker in sweet orange. All adapted strains colonized in sweet orange leaves to moderate levels and harbored a functional copy of $p t h A W 2$, which facilitates canker development

\section{Mandarins}

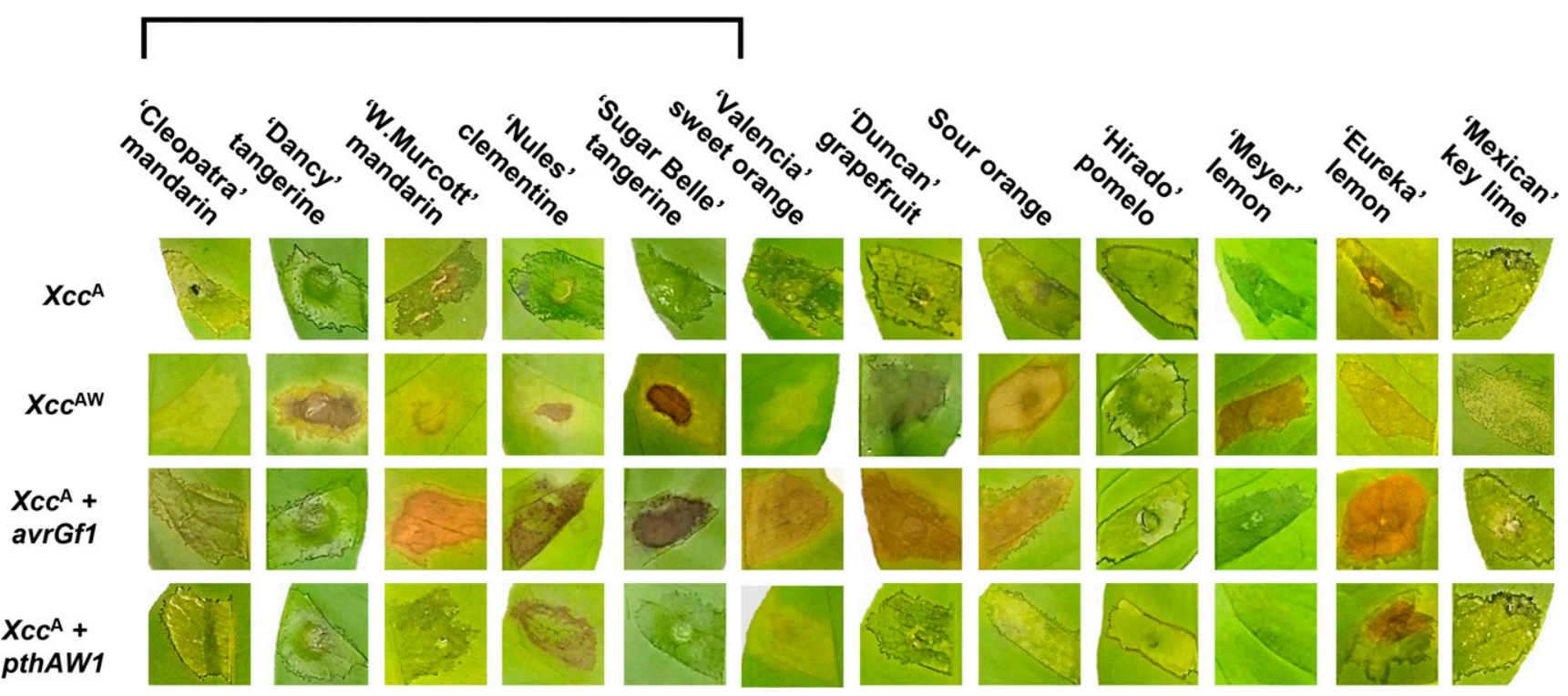

Fig. 8. Host specificity of Xanthomonas citri subsp. citri strains $X c c^{\mathrm{AW}}$ and $X c c^{\mathrm{A}}$ carrying AvrGf1 or PthAW1. Indicated citrus varieties were inoculated $\left(10^{8} \mathrm{CFU} / \mathrm{ml}\right)$ with $X c c^{\mathrm{A}}, X c c^{\mathrm{AW}}$, and $X c c^{\mathrm{A}}$ strains harboring a plasmid encoding the Xcc ${ }^{\mathrm{AW}}$ effectors avrGf1 or pthAW1. Plants were photographed 7 days postinoculation. Experiments were repeated three times (in each experiment, at least five leaves were inoculated in three plants), with similar results. 
by inducing the CsLOB1 susceptibility gene (Hu et al. 2014). Therefore, we expected that canker symptoms would appear during the adaptation, because such symptoms enhance the fitness of $X$. citri subsp. citri in susceptible hosts (Yan and Wang 2012). We hypothesized that PthAW1 or its variants or AvrGf1 might interfere with the function of PthAW2, as observed for PthAW1 and AvrGf1 interference of PthA4. Another possibility is that the signaling and metabolic pathways that lead to canker development are hindered by another $X c c^{\mathrm{AW}}$ elicitor or effector. For instance, the elicitation of immune responses by a pathogenassociated molecular pattern such as Xcc ${ }^{\mathrm{AW}}$ LPS (Y. Zhang et al. 2015) might negatively affect canker development.

Host specificity to closely related varieties by pathogen races is traditionally considered to be dictated by avr genes, which are usually T3SS effectors (Khan et al. 2016; Wichmann et al. 2005). In this study, we successfully identified an $a v r$ gene via experimental evolution, and demonstrated that PthAW1 is a novel avr gene that restricts the host range of $X$. citri subsp. citri. Our results show that the host range of $X c c^{\mathrm{AW}}$ in citrus is more likely to result from multiple factors. Although both avrGf1 and pthAWI harbor an avirulent function in sweet orange, disrupting both of these factors does not enable the bacteria to cause disease in this cultivar. In addition, although the host range of $X c c^{\mathrm{AW}}$ is restricted to lime, alemow, and pomelo (which was confirmed as a host in this study), $X c c^{\mathrm{A}}$ strains harboring either avrGfl or pthAWI are able to cause disease in mandarin varieties such as Cleopatra and Dancy that are resistant to $X c c^{\mathrm{AW}}$. Our data also demonstrate that the suppression of pustule formation by PthAW1 is restricted to a few specific citrus varieties. This study lays the foundation to further investigate the mechanism of immunity triggered by PthAW1 and utilization of the $R$ genes in future studies.

\section{MATERIALS AND METHODS}

\section{Bacterial strains and plant material.}

The bacterial strains and plasmids used in this study are listed in Table 3. Escherichia coli cells were cultured in lysogeny broth medium at $37^{\circ} \mathrm{C}$. The $X$. citri subsp. citri strains used in this study were $X c c^{\mathrm{AW}}$ strain Xcaw12879 (Jalan et al. 2013b) and $X c c^{A}$ strain 306 (da Silva et al. 2002). X. citri subsp. citri strains were cultured in NB medium, XVM2 medium, or NA plates at $28^{\circ} \mathrm{C}$. When required, media were supplemented with kanamycin $(50 \mu \mathrm{g} / \mathrm{ml})$, gentamicin $(10 \mu \mathrm{g} / \mathrm{ml})$, or spectinomycin $(100 \mu \mathrm{g} / \mathrm{ml})$. The citrus varieties used in this study were Valencia sweet orange (C. sinensis), Mexican key lime (C. aurantiifolia), Hirado pomelo (C. maxima), Cleopatra mandarin (C. reticulata), W Murcott mandarin (C. reticulata), Dancy tangerine (C. tangerina), Sugar Bell tangerine $(C$. tangerina), Nules clementine $(C$. clementina), Duncan grapefruit ( $C$. paradisi), sour orange $(C$. aurantium), Meyer lemon (C. limon), and Eureka lemon (C. limon). Sweet orange and sour orange plants were grown from seed in the Citrus Research and Education Center (Lake Alfred, FL, U.S.A.). The rest of the citrus varieties were purchased from McGill Citrus Nursery (Lake Wales, FL, U.S.A.) and Harris Citrus Nursery (Lithia, FL, U.S.A.). Plants were grown in a temperature-controlled $\left(28^{\circ} \mathrm{C}\right)$ greenhouse under natural light conditions.

\section{Plant inoculations, bacterial growth, and ion leakage.}

For plant inoculations, bacterial cultures $\left(10^{8} \mathrm{CFU} / \mathrm{ml}\right.$ to monitor symptoms and quantify ion leakage, $10^{6} \mathrm{CFU} / \mathrm{ml}$ to monitor bacterial growth) were syringe infiltrated into fully expanded young leaves ( 15 to 25 days after leaf emergence) from 1- to 3-year-old citrus plants. After being inoculated, plants were kept in a temperaturecontrolled $\left(28^{\circ} \mathrm{C}\right)$ greenhouse under natural light conditions.

To measure bacterial growth, we pooled two 0.2 -cm-diameter leaf disks from different inoculated leaves on a single plant. At least three samples from at least three different plants were homogenized in $1 \mathrm{ml}$ of $10 \mathrm{mM} \mathrm{MgCl}$. We determined the number of bacteria by plating $10 \mu \mathrm{l}$ from 10 -fold serial dilutions and counting the resulting colonies.

To quantify ion leakage, $1.5-\mathrm{cm}$-diameter leaf disks were sampled from inoculated areas and kept floated in a $10-\mathrm{ml}$ tube containing $5 \mathrm{ml}$ of double-distilled water for $4 \mathrm{~h}$ at $25^{\circ} \mathrm{C}$ with shaking. Conductivity was measured with a $\mathrm{CON} 700$ Conductivity $/{ }^{\circ} \mathrm{C} /{ }^{\circ} \mathrm{F}$ Bench Meter (Oakton Instruments, Vernon Hills, IL, U.S.A.).

\section{Experimental evolution test.}

Three independent $X c c^{\mathrm{AW}}$ cultures were repeatedly inoculated into and isolated from sweet orange. For each strain, bacteria were plated on NA media, scraped from the plate, diluted to $5 \times 10^{5} \mathrm{CFU} / \mathrm{ml}$ in $10 \mathrm{mM} \mathrm{MgCl}_{2}$, and inoculated into three leaves of previously noninoculated Valencia sweet orange plants. Then, 6 to 10 days later, $0.2-\mathrm{cm}$-diameter leaf disks were pooled from the three inoculated areas, tissues were homogenized, and serial dilutions were plated on NA plates. Bacteria were counted, scrapped from the plate, diluted to $5 \times 10^{5} \mathrm{CFU} / \mathrm{ml}$, and inoculated into another noninoculated sweet orange plant. The procedure was repeated for 30 to 45 cycles. At the end of the experiment, a single colony was selected from each of the three adapted strains for sequencing and further analysis.

\section{Mutant construction and vector-mediated expression.}

To produce deletion strains of avrG1 (XCAW_00608) and pthAW1 (XCAW_b00018), we amplified 230- to 720-bp 5' upstream and 3' downstream fragments of avrGfl or pthAWl from $X c c^{\mathrm{AW}}$ (primer sequences and details regarding the specific fragments used are presented in Table 1 and Supplementary Table S1). The 5' and $3^{\prime}$ fragments were joined together with overlap PCR and cloned into the pOK1 suicide vector (Huguet et al. 1998). Plasmids were introduced into $X c c^{\mathrm{AW}}$ by electroporation, and double-crossover transformants were identified with a twostep sucrose counter selection procedure (Gay et al. 1985). The pthAWl mutant showed significant reduction in pthAW1 expression compared with the wild-type strain (Supplementary Fig. S6).

For the expression of avrGf1, pUFR034:avrGf1 (Jalan et al. 2013a) was introduced into $X c c^{\mathrm{A}}$ by electroporation. For the expression of $p t h A W 1$, pthAW1 variants were amplified from $X c c^{\mathrm{AW}}$, $X c c^{\text {AWAdA }}$, and $X c c^{\text {AWAdC }}$; cloned into the pBBR1MCS-5 broad host vector; and electroporated into $X c c^{\mathrm{A}}$.

\section{In vitro bacterial growth curves.}

Wild-type and adapted $X c c^{\mathrm{AW}}$ cultures were grown overnight in NB medium, washed twice in distilled water, and diluted to an optical density at $600 \mathrm{~nm}\left(\mathrm{OD}_{600}\right)=0.05$ in $\mathrm{NB}$ or XVM2 (Wengelnik and Bonas 1996) media. Triplicate cultures were incubated with shaking $(150 \mathrm{rpm})$ at $28^{\circ} \mathrm{C}$ for $60 \mathrm{~h}$, and $\mathrm{OD}_{600}$ was measured with a Synergy LX multimode reader (BioTek, Winooski, VT, U.S.A.).

\section{Promoter activity.}

To construct pGUS:avrGf1 and pGUS:xopN, we amplified the promoter regions of $x o p N$ and avrGfl from genomic DNA of $X c c^{\mathrm{AW}}$ and cloned them into pGUS vector (Teper et al. 2019). pGUS constructs were introduced into wild-type and adapted $X c c^{\mathrm{AW}}$ strains. Cultures were grown in XVM2 medium for $24 \mathrm{~h}$, and GUS activity was quantified as described previously (Teper et al. 2019).

\section{Hydrolase activity, motility, biofilm formation, and $\mathrm{H}_{2} \mathrm{O}_{2}$ sensitivity experiments.}

Bacterial cultures of wild-type and adapted $X c c^{\mathrm{AW}}$ strains were grown overnight in triplicate in NB medium and diluted to $\mathrm{OD}_{600}=0.5$ in distilled water.

For motility assays, bacteria were spotted onto $0.4 \%$ NA plates and incubated at $28^{\circ} \mathrm{C}$ for 3 days. The colony diameter (the 
average of vertical and horizontal measurements) was determined (Andrade et al. 2020; Li and Wang 2011).

For hydrolase activity assays, bacteria were spotted on NA with $1 \%$ skim milk or $0.1 \%$ carboxymethyl cellulose (CMC), and plates were incubated at $28^{\circ} \mathrm{C}$ for 3 days. The CMC plates were incubated with $0.1 \%$ Congo Red, washed twice with $5 \mathrm{M} \mathrm{NaCl}$, and incubated in $0.5 \%$ acetic acid. Halo diameters were determined with a ruler.

To quantify biofilm formation, we incubated 1-ml cultures in a glass tube for $24 \mathrm{~h}$ at $28^{\circ} \mathrm{C}$. Samples were washed three times with distilled water and incubated in $0.1 \%$ crystal violet for $30 \mathrm{~min}$ (Andrade et al. 2020; Li and Wang 2012). Then, the samples were washed three times in distilled water and suspended in $70 \%$ ethanol. Crystal violet was quantified in $570 \mathrm{~nm}$ using a Synergy LX multimode reader (BioTek).

To test $\mathrm{H}_{2} \mathrm{O}_{2}$ sensitivity, we spotted serial dilutions on NA plates carrying 0,100 , and $125 \mathrm{nmol} \mathrm{H}_{2} \mathrm{O}_{2}$ and incubated them at $28^{\circ} \mathrm{C}$ for 2 days. CFU were counted and sensitivity was determined as $100 \times$ ( $\mathrm{CFU}$ in NA plates/CFU in $\mathrm{NA} \mathrm{H}_{2} \mathrm{O}_{2}$ plates).

Table 3. Bacterial strains and plasmids used in this study

\begin{tabular}{|c|c|c|}
\hline Strain or plasmid & Relevant characteristics $^{\mathrm{a}}$ & Reference \\
\hline \multicolumn{3}{|l|}{ Strain } \\
\hline \multicolumn{3}{|l|}{ Escherichia coli } \\
\hline HST08 & $\begin{array}{l}\mathrm{F}^{-} \text {, endA1, supE44, thi-1, recA1, relA1, gyrA96, phoA, } 980 \mathrm{~d} \\
\text { lacZ } \Delta \text { M15, } \Delta \text { (lacZYA-argF) U169, } \Delta \text { (mrr-hsdRMS- } \\
\text { merBC) } \Delta \text { merA, } \lambda^{-}\end{array}$ & TaKaRa Bio Inc., Kusatsu, Japan \\
\hline \multicolumn{3}{|l|}{ Xanthomonas citri subsp. citri } \\
\hline$X c c^{\mathrm{a}} 306$ & Wild-type $X c c^{\text {a }} 306$ strain & da Silva et al. 2002 \\
\hline$X c c^{\mathrm{aW}}$ Aw 12879 & Wild-type $X c c^{\mathrm{aW}}$ Aw12879 strain & Jalan et al. 2013b \\
\hline$X c c^{\mathrm{aW}} \Delta a v r G f 1$ & $\begin{array}{l}\text { Xcc } c^{\mathrm{aW}} \text { Aw12879 carrying a deletion of avrGf1 } \\
\quad \text { (XCAW_00608) }\end{array}$ & This study \\
\hline$X c c^{\mathrm{aW}} \Delta p t h A W 1$ & $\begin{array}{l}X c c^{\mathrm{aW}} \text { Aw12879 carrying a deletion of } p t h A W 1 \\
\quad \text { (XCAW_b00018) }\end{array}$ & This study \\
\hline$X c c^{\mathrm{aW}} \Delta a v r G f 1 \Delta p t h A W 1$ & $\begin{array}{l}\text { Xcc }{ }^{\mathrm{aW}} \text { Aw12879 carrying a double deletion of avrGf1 } \\
\text { (XCAW_00608)and pthAW1 (XCAW_b00018) }\end{array}$ & This study \\
\hline$X c c^{\text {aWAdA }}$ & $\begin{array}{l}\text { Adapted } X c c^{\text {aW }} \text { Aw } 12879 \text { variant isolated from sweet orange } \\
\text { after } 30 \text { infection cycles }\end{array}$ & This study \\
\hline$X c c^{\mathrm{aWAdB}}$ & $\begin{array}{l}\text { Adapted } X c c^{\mathrm{aW}} \text { Aw } 12879 \text { variant isolated from sweet orange } \\
\text { after } 30 \text { infection cycles }\end{array}$ & This study \\
\hline$X c c^{\mathrm{aWAdC}}$ & $\begin{array}{l}\text { Adapted } X c c^{\mathrm{aW}} \text { Aw } 12879 \text { variant isolated from sweet orange } \\
\text { after } 30 \text { infection cycles }\end{array}$ & This study \\
\hline \multicolumn{3}{|c|}{ (5) } \\
\hline pUFR053:AvrGf1 & $\begin{array}{l}\text { pUFR053 expressing avrGf1 (AW_00608 under the control of } \\
\text { lac promoter; } \mathrm{Gn}^{\mathrm{R}}\end{array}$ & Jalan et al. 2013a \\
\hline pOK1 & sacB sacQ mobRK2 oriR6K, suicide vector; $\mathrm{Sp}^{\mathrm{R}}$ & Huguet et al. 1998 \\
\hline pOK1:avrGf1 & $\begin{array}{l}\text { pOK1 derivative containing the } 635-\mathrm{bp} 5^{\prime} \text { and } 589-\mathrm{bp} 3^{\prime} \\
\text { flanking regions of the genomic area encoding for avrGf1 } \\
\text { (AW_00608); } \mathrm{Sp}^{\mathrm{R}}\end{array}$ & This study \\
\hline pOK1:pthAW1 & $\begin{array}{l}\text { pOK1 derivative containing the 721-bp } 5^{\prime} \text { and } 231-\mathrm{bp}(149 \text { of } \\
\text { the } 3^{\prime} \text { of the ORF and } 82 \mathrm{bp} \text { downstream from ORF) } 3^{\prime} \\
\text { flanking regions of the genomic area encoding for pthAW1 } \\
\text { (XCAW_b00018); } \mathrm{Sp}^{\mathrm{R}}\end{array}$ & This study \\
\hline pBBR1MCS-5 & Broad host expression vector; $\mathrm{Gn}^{\mathrm{R}}$ & Kovach et al. 1995 \\
\hline pBBR1MCS-5:pthAW1 & $\begin{array}{l}\text { pBBR1MCS-5 derivative for expression of } p t h A W 1 \text { from } \\
\quad X c c^{\mathrm{aW}} ; \mathrm{Gn}^{\mathrm{R}}\end{array}$ & This study \\
\hline pBBR1MCS-5:pthAWI ${ }^{\text {adA }}$ & $\begin{array}{l}\text { pBBR1MCS-5 derivative for expression of } p t h A W 1 \text { from } \\
\text { Xcc }{ }^{\text {aWAdA }} ; \mathrm{Gn}^{\mathrm{R}}\end{array}$ & This study \\
\hline pBBR1MCS-5:pthAWI ${ }^{\text {adC }}$ & $\begin{array}{l}\text { pBBR1MCS-5 derivative for expression of } p t h A W 1 \text { from } \\
\quad X c c^{\text {aWAdC }} ; \mathrm{Gn}^{\mathrm{R}}\end{array}$ & This study \\
\hline pBBR1MCS-5:pthAW1:Tn5 & $\begin{array}{l}\text { pBBR1MCS-5:pthAW1 carrying an insertion of } \mathrm{Tn} 5< \\
\text { R6K } \gamma \text { ori/KAN-2 > at position } 1,599 \text { of } p t h A W 1 \text {; used for } \\
\text { sequencing of the pthAW1 repeat array; } \mathrm{Gn}^{\mathrm{R}}, \mathrm{Km}^{\mathrm{R}}\end{array}$ & This study \\
\hline pGUS & $\begin{array}{l}\text { pBBR1MCS- } 5 \text { derivative containing gus gene followed by } \mathrm{T} 7 \\
\text { terminator cloned in reverse orientation of lac promoter; } \\
\text { used for promoter activity assay; } \mathrm{Gn}^{\mathrm{R}}\end{array}$ & Teper et al. 2019 \\
\hline pGUS:gyrA & $\begin{array}{l}\text { pGUS derivative; the 189-bp upstream region of } \\
\text { XCAW_02691/XAC1631 was cloned upstream from gus; } \\
\mathrm{Gn}^{\mathrm{R}}\end{array}$ & Teper et al. 2019 \\
\hline pGUS:hrpX & $\begin{array}{l}\text { pGUS derivative; the 474-bp upstream region of } \\
\text { XCAW_03086/XAC1266 was cloned upstream from gus; } \\
\mathrm{Gn}^{\mathrm{R}}\end{array}$ & Teper et al. 2019 \\
\hline pGUS:hrpF & $\begin{array}{l}\text { pGUS derivative; the 831-bp upstream region of } \\
\text { XCAW_00802/XAC0394 was cloned upstream from gus; } \\
\mathrm{Gn}^{\mathrm{R}}\end{array}$ & Teper et al. 2019 \\
\hline pGUS:avrGf1 & $\begin{array}{l}\text { pGUS derivative; the 1,126-bp upstream region of } \\
\text { XCAW_00608 was cloned upstream from gus; } \mathrm{Gn}^{\mathrm{R}}\end{array}$ & This study \\
\hline pGUS:xopN & $\begin{array}{l}\text { pGUS derivative; the 200-bp upstream region of } \\
\text { XCAW_01387/XAC2786 was cloned upstream from gus; } \\
\mathrm{Gn}^{\mathrm{R}}\end{array}$ & This study \\
\hline pGUS:xopAU & $\begin{array}{l}\text { pGUS derivative; the 1,000-bp upstream region of } \\
\text { XCAW_01272/XAC1171 was cloned upstream from gus; } \\
\mathrm{Gn}^{\mathrm{R}}\end{array}$ & Teper et al. 2019 \\
\hline
\end{tabular}

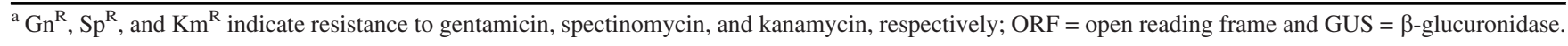




\section{EPS quantification and LPS determination.}

Bacteria were plated on NA plates and incubated at $28^{\circ} \mathrm{C}$. Four days later, the bacteria were scraped from the plate and suspended in $25 \mathrm{ml}$ of distilled water. Serial dilutions were spotted on NA plates to determine bacterial titers.

EPS quantification was performed as described elsewhere (Guo et al. 2010; Li and Wang 2012). Briefly, $50 \mathrm{ml}$ of ethanol was added to each suspension, and suspensions were incubated overnight at $-20^{\circ} \mathrm{C}$. The suspensions were filtered with Whatman paper, dried in a $65^{\circ} \mathrm{C}$ incubator, and weighed.

For LPS quantification, samples were concentrated to $10^{9}$ $\mathrm{CFU} / \mathrm{ml}$ and LPS were isolated with an LPS Isolation Kit (Sigma-Aldrich, St. Louis, MO, U.S.A.) according to the manufacturer's instructions (Yan et al. 2012). The samples were diluted 1:10 in Tris-buffered saline, separated on $12 \%$ sodium dodecyl sulfate acrylamide gel, and stained with a Silver Stain Plus Kit (Bio-Rad Laboratories, Hercules, CA, U.S.A.).

\section{DNA sequencing and analysis.}

Total DNA was extracted from bacterial cultures of wild-type and adapted $X c c^{\mathrm{AW}}$ strains with GenElute Bacterial Genomic DNA Kits (Sigma-Aldrich). The DNA samples were sent to Illumina (Novogene, Beijing, China) and Nanopore (not including the wild-type $X c c^{\mathrm{AW}}$ strain) (Grandomics Biosciences, Beijing, China).

Raw nanopore reads for three $X c c^{\mathrm{AW}}$ strains were corrected, trimmed, and then assembled into long contigs using Canu with default parameters (Koren et al. 2017). To further improve the quality of the assembled genomes, we resequenced full genomes for three $X c c^{\mathrm{AW}}$ strains using the Illumina Novaseq 6000 sequencing platform. After removing adaptor sequences and trimming and removing low-quality reads using Sickle (Joshi and Fass 2011), we mapped high-quality short reads to assembled genomes using bowtie2 (Langmead and Salzberg 2012), then corrected the genomes using Pilon (Walker et al. 2014). We mapped highquality short (Illumina) and long (Nanopore) reads for the three $X c c^{\mathrm{AW}}$ strains to the $X c c^{\mathrm{AW}}$ reference genome (Jalan et al. 2013a) using bowtie2 (Langmead and Salzberg 2012) and minimap2 (Li 2018), then generated genomic variants (single-nucleotide polymorphism and insertion/deletion [INDEL]) using samtools/ bcftools pipline (Li et al. 2009).

To validate the genome analyses, we determined point mutations or short INDEL mutations using Sanger sequencing. Fragments were amplified from wild-type and adapted $X c c^{\mathrm{AW}}$ strains with primers corresponding to the 400- to 600-bp flanking region of the mutated area of each mutation with CloneAmp HiFi PCR Premix (TaKaRa, Kyoto, Japan), and sequencing was performed by Eton Bioscience (San Diego, CA, U.S.A.). To determine the sequence of the pthAW1 homologs, full-length $p t h A W 1$ was amplified from wild-type and adapted $X c c^{\mathrm{AW}}$ strains and cloned into pBBR1MCS-5 (Kovach et al. 1995). To get full coverage of the repeat area, pthAWl was inserted with Tn5 transposon with EZ-Tn5 < R6K $\gamma$ ori/KAN-2 > Insertion Kit (Lucigen, Middleton, WI, U.S.A.). The sequences of the pthAWl homologs were determined with gene-specific primers and primers directed to the transposon insertion areas.

\section{AUTHOR-RECOMMENDED INTERNET RESOURCE}

BioRender: https://biorender.com

\section{LITERATURE CITED}

Abe, V. Y., and Benedetti, C. E. 2016. Additive roles of PthAs in bacterial growth and pathogenicity associated with nucleotide polymorphisms in effector-binding elements of citrus canker susceptibility genes. Mol. Plant Pathol. 17:1223-1236.
Alfano, J. R., and Collmer, A. 2004. Type III secretion system effector proteins: Double agents in bacterial disease and plant defense. Annu. Rev. Phytopathol. 42:385-414.

An, S.-Q., Potnis, N., Dow, M., Vorhölter, F.-J., He, Y.-Q., Becker, A., Teper, D., Li, Y., Wang, N., Bleris, L., and Tang, J.-L. 2020. Mechanistic insights into host adaptation, virulence and epidemiology of the phytopathogen Xanthomonas. FEMS Microbiol. Rev. 44:1-32.

Andrade, M. O., Farah, C. S., and Wang, N. 2014. The post-transcriptional regulator $r s m A / c s r A$ activates T3SS by stabilizing the 5' UTR of $h r p G$, the master regulator of hrp/hrc genes, in Xanthomonas. PLoS Pathog. 10:e1003945.

Andrade, M. O., Pang, Z., Achor, D. S., Wang, H., Yao, T., Singer, B. H., and Wang, N. 2020. The flagella of 'Candidatus Liberibacter asiaticus' and its movement in planta. Mol. Plant Pathol. 21:109-123.

Balint-Kurti, P. 2019. The plant hypersensitive response: Concepts, control and consequences. Mol. Plant Pathol. 20:1163-1178.

Bäumler, A., and Fang, F. C. 2013. Host specificity of bacterial pathogens. Cold Spring Harb. Perspect. Med. 3:a010041.

Brunings, A. M., and Gabriel, D. W. 2003. Xanthomonas citri: Breaking the surface. Mol. Plant Pathol. 4:141-157.

Cesari, S. 2018. Multiple strategies for pathogen perception by plant immune receptors. New Phytol. 219:17-24.

da Silva, A. C. R., Ferro, J. A., Reinach, F. C., Farah, C. S., Furlan, L. R., Quaggio, R. B., Monteiro-Vitorello, C. B., Van Sluys, M. A., Almeida, N. F., Alves, L. M. C., do Amaral, A. M., Bertolini, M. C., Camargo, L. E. A., Camarotte, G., Cannavan, F., Cardozo, J., Chambergo, F., Ciapina, L. P., Cicarelli, R. M. B., Coutinho, L. L., Cursino-Santos, J. R., El-Dorry, H., Faria, J. B., Ferreira, A. J. S., Ferreira, R. C. C., Ferro, M. I. T., Formighieri, E. F., Franco, M. C., Greggio, C. C., Gruber, A., Katsuyama, A. M., Kishi, L. T., Leite, R. P., Lemos, E. G. M., Lemos, M. V. F., Locali, E. C., Machado, M. A., Madeira, A. M. B. N., Martinez-Rossi, N. M., Martins, E. C., Meidanis, J., Menck, C. F. M., Miyaki, C. Y., Moon, D. H., Moreira, L. M., Novo, M. T. M., Okura, V. K., Oliveira, M. C., Oliveira, V. R., Pereira, H. A., Rossi, A., Sena, J. A. D., Silva, C., de Souza, R. F., Spinola, L. A. F., Takita, M. A., Tamura, R. E., Teixeira, E. C., Tezza, R. I. D., Trindade dos Santos, M., Truffi, D., Tsai, S. M., White, F. F., Setubal, J. C., and Kitajima, J. P. 2002. Comparison of the genomes of two Xanthomonas pathogens with differing host specificities. Nature 417:459-463.

Denancé, N., Szurek, B., Doyle, E. L., Lauber, E., Fontaine-Bodin, L., Carrère, S., Guy, E., Hajri, A., Cerutti, A., Boureau, T., Poussier, S., Arlat, M., Bogdanove, A. J., and Noël, L. D. 2018. Two ancestral genes shaped the Xanthomonas campestris TAL effector gene repertoire. New Phytol. 219:391-407.

Doyle, E. L., Stoddard, B. L., Voytas, D. F., and Bogdanove, A. J. 2013. TAL effectors: Highly adaptable phytobacterial virulence factors and readily engineered DNA-targeting proteins. Trends Cell Biol. 23:390398.

Driessen, A. J., Fekkes, P., and van der Wolk, J. P. 1998. The Sec system. Curr. Opin. Microbiol. 1:216-222.

Duan, S., Jia, H., Pang, Z., Teper, D., White, F., Jones, J., Zhou, C., and Wang, N. 2018. Functional characterization of the citrus canker susceptibility gene CsLOB1. Mol. Plant Pathol. 19:1908-1916.

Erkes, A., Reschke, M., Boch, J., and Grau, J. 2017. Evolution of transcription activator-like effectors in Xanthomonas oryzae. Genome Biol. Evol. 9:1599-1615.

Favaro, M. A., Molina, M. C., Roeschlin, R. A., Gadea, J., Gariglio, N., and Marano, M. R. 2020. Different responses in mandarin cultivars uncover a role of cuticular waxes in the resistance to citrus canker. Phytopathology 110:1791-1801.

Ference, C. M., Gochez, A. M., Behlau, F., Wang, N., Graham, J. H., and Jones, J. B. 2018. Recent advances in the understanding of Xanthomonas citri ssp. citri pathogenesis and citrus canker disease management. Mol. Plant Pathol. 19:1302-1318.

Ference, C. M., Manthey, J. A., Narciso, J. A., Jones, J. B., and Baldwin, E. A. 2020. Detection of phenylpropanoids in citrus leaves produced in response to Xanthomonas citri subsp. citri. Phytopathology 110: 287-296.

Flor, H. H. 1971. Current status of the gene-for-gene concept. Annu. Rev. Phytopathol. 9:275-296.

Gassmann, W., and Bhattacharjee, S. 2012. Effector-triggered immunity signaling: From gene-for-gene pathways to protein-protein interaction networks. Mol. Plant-Microbe Interact. 25:862-868.

Gay, P., Le Coq, D., Steinmetz, M., Berkelman, T., and Kado, C. I. 1985. Positive selection procedure for entrapment of insertion sequence elements in gram-negative bacteria. J. Bacteriol. 164:918-921. 
Gill, U. S., Lee, S., and Mysore, K. S. 2015. Host versus nonhost resistance: Distinct wars with similar arsenals. Phytopathology 105:580-587.

Gochez, A. M., Huguet-Tapia, J. C., Minsavage, G. V., Shantaraj, D., Jalan, N., Strauß, A., Lahaye, T., Wang, N., Canteros, B. I., Jones, J. B., and Potnis, N. 2018. Pacbio sequencing of copper-tolerant Xanthomonas citri reveals presence of a chimeric plasmid structure and provides insights into reassortment and shuffling of transcription activator-like effectors among $X$. citri strains. BMC Genomics 19:16.

Gochez, A. M., Minsavage, G. V., Potnis, N., Canteros, B. I., Stall, R. E., and Jones, J. B. 2015. A functional XopAG homologue in Xanthomonas fuscans pv. aurantifolii strain C limits host range. Plant Pathol. 64:12071214.

Guo, Y., Figueiredo, F., Jones, J., and Wang, N. 2011. HrpG and HrpX play global roles in coordinating different virulence traits of Xanthomonas axonopodis pv. citri. Mol. Plant-Microbe Interact. 24:649-661.

Guo, Y., Sagaram, U. S., Kim, J. S., and Wang, N. 2010. Requirement of the galU gene for polysaccharide production by and pathogenicity and growth in planta of Xanthomonas citri subsp. citri. Appl. Environ. Microbiol. 76:2234-2242.

Hu, J., and Wang, N. 2016. Evaluation of the spatiotemporal dynamics of oxytetracycline and its control effect against citrus huanglongbing via trunk injection. Phytopathology 106:1495-1503.

Hu, Y., Zhang, J., Jia, H., Sosso, D., Li, T., Frommer, W. B., Yang, B., White, F. F., Wang, N., and Jones, J. B. 2014. Lateral organ boundaries 1 is a disease susceptibility gene for citrus bacterial canker disease. Proc. Natl. Acad. Sci. U.S.A. 111:E521-E529.

Huguet, E., Hahn, K., Wengelnik, K., and Bonas, U. 1998. hpaA mutants of Xanthomonas campestris pv. vesicatoria are affected in pathogenicity but retain the ability to induce host-specific hypersensitive reaction. Mol. Microbiol. 29:1379-1390.

Hutin, M., Pérez-Quintero, A. L., Lopez, C., and Szurek, B. 2015. MorTAL Kombat: The story of defense against TAL effectors through loss-of-susceptibility. Front. Plant Sci. 6:535.

Jacques, M.-A., Arlat, M., Boulanger, A., Boureau, T., Carrère, S., Cesbron, S., Chen, N. W. G., Cociancich, S., Darrasse, A., Denancé, N., Fischer-Le Saux, M., Gagnevin, L., Koebnik, R., Lauber, E., Noël, L. D., Pieretti, I., Portier, P., Pruvost, O., Rieux, A., Robène, I., Royer, M., Szurek, B., Verdier, V., and Vernière, C. 2016. Using Ecology, Physiology, and Genomics to Understand Host Specificity in Xanthomonas. Annu. Rev. Phytopathol. 54:163-187.

Jalan, N., Kumar, D., Andrade, M. O., Yu, F., Jones, J. B., Graham, J. H., White, F. F., Setubal, J. C., and Wang, N. 2013a. Comparative genomic and transcriptome analyses of pathotypes of Xanthomonas citri subsp. citri provide insights into mechanisms of bacterial virulence and host range. BMC Genomics 14:551.

Jalan, N., Kumar, D., Yu, F., Jones, J. B., Graham, J. H., and Wang, N. 2013b. Complete genome sequence of Xanthomonas citri subsp. citri strain Aw12879, a restricted-host-range citrus canker-causing bacterium. Genome Announce. 1:e0235-13.

Ji, Z., Ji, C., Liu, B., Zou, L., Chen, G., and Yang, B. 2016. Interfering TAL effectors of Xanthomonas oryzae neutralize R-gene-mediated plant disease resistance. Nat. Commun. 7:13435.

Jia, H., Orbović, V., and Wang, N. 2019. CRISPR-LbCas12a-mediated modification of citrus. Plant Biotechnol. J. 17:1928-1937.

Jia, H., and Wang, N. 2014. Xcc-facilitated agroinfiltration of citrus leaves: A tool for rapid functional analysis of transgenes in citrus leaves. Plant Cell Rep. 33:1993-2001.

Jia, H., and Wang, N. 2020. Generation of homozygous canker-resistant citrus in the T0 generation using CRISPR-SpCas9p. Plant Biotechnol. J. 18:1990-1992.

Jia, H., Xu, J., Orbović, V., Zhang, Y., and Wang, N. 2017a. Editing citrus genome via SaCas9/sgRNA system. Front. Plant Sci. 8:2135.

Jia, H., Zhang, Y., Orbović, V., Xu, J., White, F. F., Jones, J. B., and Wang, N. 2017b. Genome editing of the disease susceptibility gene CsLOB1 in citrus confers resistance to citrus canker. Plant Biotechnol. J. 15:817823.

Joshi, N., and Fass, J. 2011. Sickle: A sliding-window, adaptive, qualitybased trimming tool for FastQ files (version 1.33). https://github.com/ najoshi/sickle

Khan, M., Subramaniam, R., and Desveaux, D. 2016. Of guards, decoys, baits and traps: Pathogen perception in plants by type III effector sensors. Curr. Opin. Microbiol. 29:49-55.

Kim, N. H., Choi, H. W., and Hwang, B. K. 2010. Xanthomonas campestris pv. vesicatoria effector AvrBsT induces cell death in pepper, but suppresses defense responses in tomato. Mol. Plant-Microbe Interact. 23: 1069-1082.

Koren, S., Walenz, B. P., Berlin, K., Miller, J. R., Bergman, N. H., and Phillippy, A. M. 2017. Canu: Scalable and accurate long-read assembly via adaptive $k$-mer weighting and repeat separation. Genome Res. 27: 722-736.

Kovach, M. E., Elzer, P. H., Hill, D. S., Robertson, G. T., Farris, M. A., Roop, R. M., 2nd, and Peterson, K. M. 1995. Four new derivatives of the broad-host-range cloning vector pBBR1MCS, carrying different antibiotic-resistance cassettes. Gene 166:175-176.

Langmead, B., and Salzberg, S. L. 2012. Fast gapped-read alignment with Bowtie 2. Nat. Methods 9:357-359.

Li, H. 2018. Minimap2: Pairwise alignment for nucleotide sequences. Bioinformatics 34:3094-3100.

Li, H., Handsaker, B., Wysoker, A., Fennell, T., Ruan, J., Homer, N., Marth, G., Abecasis, G., Durbin, R., and 1000 Genome Project Data Processing Subgroup. 2009. The Sequence Alignment/Map format and SAMtools. Bioinformatics 25:2078-2079.

Li, J., Kolbasov, V., Lee, D., Pang, Z., Yixiao, H., Collins, N., and Wang, $\mathrm{N}$. Residue dynamics of streptomycin in citrus delivered by foliar spray and trunk injection and effect on 'Candidatus Liberibacter asiaticus' titer. Phytopathology. In press.

Li, J., Pang, Z., Duan, S., Lee, D., Kolbasov, V. G., and Wang, N. 2019. The in planta effective concentration of oxytetracycline against 'Candidatus Liberibacter asiaticus' for suppression of citrus huanglongbing. Phytopathology 109:2046-2054.

Li, J., and Wang, N. 2011. Genome-wide mutagenesis of Xanthomonas axonopodis pv. citri reveals novel genetic determinants and regulation mechanisms of biofilm formation. PLoS One 6:e21804.

Li, J., and Wang, N. 2012. The gpsX gene encoding a glycosyltransferase is important for polysaccharide production and required for full virulence in Xanthomonas citri subsp. citri. BMC Microbiol. 12:31.

Li, J., and Wang, N. 2014. Foliar application of biofilm formationinhibiting compounds enhances control of citrus canker caused by Xanthomonas citri subsp. citri. Phytopathology 104:134-142.

Li, L., Li, J., Zhang, Y., and Wang, N. 2019. Diffusible signal factor (DSF)mediated quorum sensing modulates expression of diverse traits in Xanthomonas citri and responses of citrus plants to promote disease. BMC Genomics 20:55.

Patané, J. S. L., Martins, J., Jr., Rangel, L. T., Belasque, J., Digiampietri, L. A., Facincani, A. P., Ferreira, R. M., Jaciani, F. J., Zhang, Y., Varani, A. M., Almeida, N. F., Wang, N., Ferro, J. A., Moreira, L. M., and Setubal, J. C. 2019. Origin and diversification of Xanthomonas citri subsp. citri pathotypes revealed by inclusive phylogenomic, dating, and biogeographic analyses. BMC Genomics 20:700.

Peng, A., Chen, S., Lei, T., Xu, L., He, Y., Wu, L., Yao, L., and Zou, X. 2017. Engineering canker-resistant plants through CRISPR/Cas9-targeted editing of the susceptibility gene $C S L O B 1$ promoter in citrus. Plant Biotechnol. J. 15:1509-1519.

Perez-Quintero, A. L., and Szurek, B. 2019. A decade decoded: Spies and hackers in the history of TAL effectors research. Annu. Rev. Phytopathol. 57:459-481.

Remigi, P., Masson-Boivin, C., and Rocha, E. P. C. 2019. Experimental evolution as a tool to investigate natural processes and molecular functions. Trends Microbiol. 27:623-634.

Rigano, L. A., Siciliano, F., Enrique, R., Sendín, L., Filippone, P., Torres, P. S., Qüesta, J., Dow, J. M., Castagnaro, A. P., Vojnov, A. A., and Marano, M. R. 2007. Biofilm formation, epiphytic fitness, and canker development in Xanthomonas axonopodis pv. citri. Mol. PlantMicrobe Interact. 20:1222-1230.

Roeschlin, R. A., Uviedo, F., García, L., Molina, M. C., Favaro, M. A., Chiesa, M. A., Tasselli, S., Franco-Zorrilla, J. M., Forment, J., Gadea, J., and Marano, M. R. 2019. PthA $4{ }^{\mathrm{AT}}$, a 7.5-repeats transcription activator-like (TAL) effector from Xanthomonas citri ssp. citri, triggers citrus canker resistance. Mol. Plant Pathol. 20:1394-1407.

Rybak, M., Minsavage, G. V., Stall, R. E., and Jones, J. B. 2009. Identification of Xanthomonas citri ssp. citri host specificity genes in a heterologous expression host. Mol. Plant Pathol. 10:249-262.

Schornack, S., Ballvora, A., Gürlebeck, D., Peart, J., Baulcombe, D., Ganal, M., Baker, B., Bonas, U., and Lahaye, T. 2004. The tomato resistance protein Bs4 is a predicted non-nuclear TIR-NB-LRR protein that mediates defense responses to severely truncated derivatives of AvrBs4 and overexpressed AvrBs3. Plant J. 37:46-60.

Schwartz, A. R., Potnis, N., Timilsina, S., Wilson, M., Patané, J., Martins, J., Jr., Minsavage, G. V., Dahlbeck, D., Akhunova, A., Almeida, N., Vallad, G. E., Barak, J. D., White, F. F., Miller, S. A., Ritchie, D., Goss, E., Bart, R. S., Setubal, J. C., Jones, J. B., and Staskawicz, B. J. 2015. Phylogenomics of Xanthomonas field strains infecting pepper and tomato reveals diversity in effector repertoires and identifies determinants of host specificity. Front. Microbiol. 6:535.

Sun, X., Stall, R. E., Jones, J. B., Cubero, J., Gottwald, T. R., Graham, J. H., Dixon, W. N., Schubert, T. S., Chaloux, P. H., Stromberg, V. K., Lacy, 
G. H., and Sutton, B. D. 2004. Detection and characterization of a new strain of citrus canker bacteria from Key/Mexican lime and alemow in South Florida. Plant Dis. 88:1179-1188.

Teper, D., and Wang, N. 2021. Consequences of adaptation of TAL effectors on host susceptibility to Xanthomonas. PLoS Genet. 17:e1009310.

Teper, D., Xu, J., Li, J., and Wang, N. 2020. The immunity of Meiwa kumquat against Xanthomonas citri is associated with a known susceptibility gene induced by a transcription activator-like effector. PLoS Pathog. 16: e1008886.

Teper, D., Zhang, Y., and Wang, N. 2019. TfmR, a novel TetR-family transcriptional regulator, modulates the virulence of Xanthomonas citri in response to fatty acids. Mol. Plant Pathol. 20:701-715.

Timilsina, S., Potnis, N., Newberry, E. A., Liyanapathiranage, P., IruegasBocardo, F., White, F. F., Goss, E. M., and Jones, J. B. 2020. Xanthomonas diversity, virulence and plant-pathogen interactions. Nat. Rev. Microbiol. 18:415-427.

Trivedi, P., and Wang, N. 2014. Host immune responses accelerate pathogen evolution. ISME J. 8:727-731.

Vernière, C., Hartung, J. C., Pruvost, O. P., Civerolo, E. L., Alvarez, A. M., Maestri, P., and Luisetti, J. 1998. Characterization of phenotypically distinct strains of Xanthomonas axonopodis pv. citri from Southwest Asia. Eur. J. Plant Pathol. 104:477-487.

Walker, B. J., Abeel, T., Shea, T., Priest, M., Abouelliel, A., Sakthikumar, S., Cuomo, C. A., Zeng, Q., Wortman, J., Young, S. K., and Earl, A. M. 2014. Pilon: An integrated tool for comprehensive microbial variant detection and genome assembly improvement. PLoS One 9:e112963.

Wang, N. 2019. The citrus huanglongbing crisis and potential solutions. Mol. Plant 12:607-609.

Wang, N., Stelinski, L. L., Pelz-Stelinski, K. S., Graham, J. H., and Zhang, Y. 2017. Tale of the huanglongbing disease pyramid in the context of the citrus microbiome. Phytopathology 107:380-387.

Wei, C.-F., Kvitko, B. H., Shimizu, R., Crabill, E., Alfano, J. R., Lin, N.-C., Martin, G. B., Huang, H.-C., and Collmer, A. 2007. A Pseudomonas syringae pv. tomato DC3000 mutant lacking the type III effector HopQ1-1 is able to cause disease in the model plant Nicotiana benthamiana. Plant J. 51:32-46.

Wengelnik, K., and Bonas, U. 1996. HrpXv, an AraC-type regulator, activates expression of five of the six loci in the hrp cluster of Xanthomonas campestris pv. vesicatoria. J. Bacteriol. 178:3462-3469.

Wheatley, M., and Yang, Y. Versatile applications of the CRISPR/Cas toolkit in plant pathology and disease management. Phytopathology. In press.

Wichmann, G., Ritchie, D., Kousik, C. S., and Bergelson, J. 2005. Reduced genetic variation occurs among genes of the highly clonal plant pathogen Xanthomonas axonopodis pv. vesicatoria, including the effector gene avrBs2. Appl. Environ. Microbiol. 71:2418-2432.
Woolhouse, M. E., Taylor, L. H., and Haydon, D. T. 2001. Population biology of multihost pathogens. Science 292:1109-1112.

Xin, X.-F., Kvitko, B., and He, S. Y. 2018. Pseudomonas syringae: What it takes to be a pathogen. Nat. Rev. Microbiol. 16:316-328.

Yan, Q., Hu, X., and Wang, N. 2012. The novel virulence-related gene $n l x A$ in the lipopolysaccharide cluster of Xanthomonas citri ssp. citri is involved in the production of lipopolysaccharide and extracellular polysaccharide, motility, biofilm formation and stress resistance. Mol. Plant Pathol. 13:923-934.

Yan, Q., and Wang, N. 2012. High-throughput screening and analysis of genes of Xanthomonas citri subsp. citri involved in citrus canker symptom development. Mol. Plant-Microbe Interact. 25:69-84.

Yim, L., Moukadiri, I., Björk, G. R., and Armengod, M.-E. 2006. Further insights into the tRNA modification process controlled by proteins MnmE and GidA of Escherichia coli. Nucleic Acids Res. 34:5892-5905.

Yuan, X., Chen, C., Bassanezi, R., Wu, F., Feng, Z., Shi, D., Du, Y., Zhong, L., Zhong, B., Lu, Z., Li, J., Song, X., Hu, Y., Ouyang, Z., Liu, X., Xie, J., Rao, X., Wang, X., Wu, D., Guan, Z., and Wang, N. Region-wide comprehensive implementation of roguing infected trees, tree replacement, and insecticide applications successfully controls citrus HLB. Phytopathology. In press.

Zhang, J., Huguet-Tapia, J. C., Hu, Y., Jones, J., Wang, N., Liu, S., and White, F. F. 2017. Homologues of CsLOB1 in citrus function as disease susceptibility genes in citrus canker. Mol. Plant Pathol. 18:798-810.

Zhang, J., Yin, Z., and White, F. 2015. TAL effectors and the executor $R$ genes. Front. Plant Sci. 6:641.

Zhang, Y., Jalan, N., Zhou, X., Goss, E., Jones, J. B., Setubal, J. C., Deng, X., and Wang, N. 2015. Positive selection is the main driving force for evolution of citrus canker-causing Xanthomonas. ISME J. 9:2128-2138.

Zhang, Y., Lubberstedt, T., and Xu, M. 2013. The genetic and molecular basis of plant resistance to pathogens. J. Genet. Genomics 40:23-35.

Zhang, Y., Teper, D., Xu, J., and Wang, N. 2019. Stringent response regulators (p)ppGpp and DksA positively regulate virulence and host adaptation of Xanthomonas citri. Mol. Plant Pathol. 20:1550-1565.

Zhou, X., Hu, X., Li, J., and Wang, N. 2015. A novel periplasmic protein, VrpA, contributes to efficient protein secretion by the type III secretion system in Xanthomonas spp. Mol. Plant-Microbe Interact. 28:143-153.

Zhou, X., Teper, D., Andrade, M. O., Zhang, T., Chen, S., Song, W.-Y., and Wang, N. 2018. A phosphorylation switch on lon protease regulates bacterial type iii secretion system in host. MBio 9:e02146-17.

Zhou, X., Yan, Q., and Wang, N. 2017. Deciphering the regulon of a GntR family regulator via transcriptome and ChIP-exo analyses and its contribution to virulence in Xanthomonas citri. Mol. Plant Pathol. 18: 249-262. 